(Aus dem patholog. Institut des Friedrichstädt. Krankenhauses zu Dresden. Director: Ober-Med.-Rath Dr. Schmorl.)

\title{
Ueber die Veränderungen der Ovarien bei syncy- tialen Tumoren und Blasenmole, zugleich ein Beitrag zur Histogenese der Luteïncysten.
}

\author{
Von
}

Dr. med. E. Runge,

jetzt Vol.-Assistent a. d. geburtsh.-gyn. Universitäts-Poliklinik der Kgl. Charité.

(Mit 2 Abbildungen im Text.)

Ueberblickt man die Literatur des letzten Jahrzehntes auf dem Gebiete der Gynäkologie, so findet man zeitweise geradezu eine Hochfluth von Berichten über Fälle von syncytialen Tumoren, denen sich Erklärungsversuche über den anatomischen Aufbau, sowie die Pathogenese und die Aetiologie dieser Geschwülste in mehr oder weniger umfangreichem Maasse anschliessen. Ueber den ersteren Punkt sind sich die Autoren heute wohl ziemlich einig, weniger leider über den letzteren.

Während sich die Berichte über diese Tumoren und die mit ihnen wohl sicher in genetischem Zusammenhange stehenden Blasenmolen anfangs ausschliesslich mit diesen selbst beschäftigten, haben in den letaten Jahren vereinzelte Beobachter auch auf eine Veränderung aufmerksam gemacht, die nach ihrer Ansicht nicht ganz ohne $\mathrm{Zu}-$ sammenhang mit diesen Geschwülsten ist. Sie fanden nämlich letztere auffällig oft mit cystischer Degeneration der Ovarien combinirt. Derjenige wohl, welcher zuerst die Aufmerksamkeit hierauf lenkte, war Marchand (12), denn er sagt bei der Besprechung der syncytialen Tumoren: "Auffallend ist ferner in mehreren Fällen das gleichzeitige Vorhandensein von cystischer Entartung der Eier- 
34 Runge, Ueber die Veränderungen der Ovarien bei syncytialen Tumoren

stöcke". Dieselbe Beobachtung machten dann auch andere Forscher bei Blasenmole und sprachen die Vermuthung aus, dass letztere möglicherweise ihren Grund in einer primären Erkrankung der Eierstöcke haben könnte. Den Beweis hierfür konnten sie leider nicht erbringen. In letzter Zeit haben sich dann einige Beobachter der dankenswerthen Nühe unterzogen, bei Blasenmole bezw. syncytialen Tumoren die Eierstöcke genauer zu untersuchen. Hierzu gehören vor Allem Marchand (11 u. 13), Neumann (18), Goebel (8), Fiedler (4), Poten-Vassmer (20), SchallerPförringer (21) und Stoeckel (27).

Whe ich auf die Befunde dieser Forscher näher eingehe, möchte ich zuerst kurz angeben, was ich über Veränderungen der Ovarien bei syncytialen Tumoren und Blasenmole in der mir zugängigen Literatur finden konnte. Unter 144 Fällen von syncytialen Tumoren existirte bei 81 überhaupt keine Angabe über die Ovarien. Die übrigen 63 Fälle lassen sich in zwei grosse Gruppen sondern, einmal solche, wo die Orarien normal gefunden wurden, und auf der anderen Seite die, wo cystische Entartung derselben vorlag. Unter die erste Gruppe fallen 11 Fälle, wo der Tastbefund nichts Abnormes an den Ovarien ergab, und 28 Eälle, wo auch die Inspection bei Operationen oder Sectionen an den Ovarien nichts Pathologisches oder wenigstens keine cystische Degeneration feststellen konnte. In den übrigen 24 Fällen waren die Eierstöcke mehr oder weniger ausgesprochen cystisch entartet.

Bei Blasenmolen fehlte unter 28 Fällen, über die ich in der Literatur berichtet fand, 16 mal überhaupt jede Angabe über die Ovarien, und 12 mal zeigten dieselben cystische Degeneration.

Durch das vielfache, vollständige Feblen von Angaben ist natürlich eine exacte Feststellung der ovariellen Veränderungen nicht möglich. Auffallen wird immerhin das mehr als gewöhnlich zahlreiche Auftreten derselben.

Besonders wird dies der Fall sein, wenn man bedenkt, dass bei der combinirten Untersuchung wohl manches Ovarium als normal erscheinen kann und trotzdem, wenn auch in geringem Maasse, cystisch degenerirt ist, da ja eine Vergrösserung desselben nicht unbedingt mit dieser Entartung verbunden sein muss, and eine geringe Grössenzunahme sehr wohl dem tastenden Finger entgehen kann. Selbst in den Fällen, wo durch die Ocularinspection die Ovarien als normal erkannt wurden, würde wohl mehr als eins von ihnen sich cystisch degenerirt erwiesen haben, wenn eine mi- 
kroskopische Untersuchung daraufhin stattgefunden hätte, was aber leider gemäss den Angaben in keinem der Fälle geschehen ist.

Unter diesem Gesichtswinkel betrachtet, erscheint das vielfache Vorkommen von cystischer Entartung der Eierstöcke bei syncytialen Tumoren und Blasenmolen höchst auffällig, und ist es wohl nicht unberechtigt, wenn man die Vermuthung ausspricht, dass hier ein innerer Zusammenhang bestehen dürfte.

Ich möchte nach dieser Abschweifung nun auf die Befunde zurückkommen, welche diejenigen Forscher erhoben haben, die eine genavere Untersuchung der Ovarien vorgenommen haben.

Marchand (11) fand in einem Falle von syncytialem Tumor das eine Ovarium bedeutend vergrössert durch eine stark gallertige Quellung des Parenchyms und einige cystische, innen glattwandige Hohlräume mit stark vascularisirter Innenfläche; welche mit gelben Auflagerungen bedeckt war. Das andere Ovarium war stark vergrössert, enthielt einige cystische HohIräume und ein Corpus luteum verum. In einem anderen Falle (13) von syncytialem Tumor fand ex in dem einen Ovarium eine kirschgrosse Corpus-luteumCyste.

Neumann (18) beschreibt die Ovarien bei einem syncytialen Tumor als in grosse, cystische Tumoren von weicher, schwappender Consistenz umgewandelt. Sie bestanden aus mehrkammerigen Cysten, die theils mit hellem, wässerigen Inhalt, theils mit einer dicken Gallerte gefüllt waren. Am rechten Ovarium fand sich in der Peripherie ein grösserer, solider Antheil, der ödematös und fast homogen erschien. In demselben waren vereinzelte, mit Blut durchsetzte Follikel enthalten und Reste von solchen, welche in Folge von Veränderung des Blutfarbstoffes rostgelb gefärbt waren. Mikroskopisch erwiesen die Ovarien sich als von Follikeln, durchsetzt. Das Stroma enthielt grosse Gruppen von rundlichen, zelligen Gebilden mit hellem Protoplasma und kleinen polygonalen Kernen, zwischen denen sich einzelne Septa ron Ovarialstroma erstreckten. Stellenweise sah man gelbe körnige Massen. Neumann hält diese Stellen für entstehende Corpora candicantia, indem er annimmt, dass die deciduaähnlichen Zellen die gewucherten Elemente der Theca folliculi darstellen, zwischen denen die sogenannten "Luteïnzellen" liegen. In einem Falle von Blasenmole, uber den Neumann in derselben Abhandlung berichtet, fänd er ähnliche Gebilde in den Ovarien, wie in obigem Falle.

Goebel (8) sah bei einer Blasenmole das linke Ovarium in 
eine gut faustgrosse Cyste umgewandelt, in deren Wand der stark ausgedehnte und verdünnte Rest des Ovariums eingezogen war. Mikroskopisch erwies sich die Cyste als ein Kystoma simplex, das in seiner bindegewebigen Wand, da wo das ausgezogene Ovarialstroma sass, mehrere kleine, kaum erbsengrosse, secundäre Cystchen trug, die er für hydropische Graaf'sche Follikel hält.

Fiedler (4) fand bei einem syneytialen Tumor beiderseits die Ovarien in kindskopfgrosse Tumoren umgewandelt, welche sich aus multiplen, kleineren Cysten zusammensetzten. In den stark verdünnten Cystenwandungen bemerkte er beiderseits an zahlreichen Stellen ausgedehnte, unregelmässige, tiefdunkelrothe Herde. Mikroskopisch fand er die Cysten mit einer mehrfachen Schicht von rundlichen Zellen ausgekleidet, die eine auffallende Aehnlichkeit mit Granulosazellen besassen.

Poten und Vassmer (20) sahen bei einer Blasenmole die Ovarien in Tumoren von Kleinapfelgrösse umgewandelt. Die Oberfläche derselben zeigte multiple erbsen- bis wallnussgrosse, halbkugelige Prominenzen, die mit theils gelblich-gelatinösem, theils dunkel-bräunlichem Inhalt gefüllten Cysten entsprachen, welche vorwiegend die Rindensubstanz einnahmen und das Ovarialgewebe stellenweise bis auf schmale Septa reducirt hatten. Auch die Marksubstanz der Ovarien war von ähnlichen, aber kleineren Cystchen durchsetzt. Selten nur zeigte die Innenfläche der grossen, wie der kleinen Cysten eine Fältelung. An zahlreichen Stellen der Oberfläche des einen Ovariums sah man kleine, stecknadelkopfgrosse, gelbliche Knötchen, sowie mehr flache Excrescenzen, die häufig eine rothe, blutfarbene, leicht erhabene Peripherie und weissgelbliches Centrum zeigten. Mikroskopisch bestand die Wandung der erwähnten Cysten deutlich aus zwei Schichten, einer äusseren, gefässreichen Bindegewebsschicht und einer inneren, verschieden breiten Sehicht, die aus grossen, platten, epithelähnlichen Zellen mit grossem Kern, deutlichem Kernkörperchen und diffus sich färbendem Protoplasma bestand. Häufig waren diese Zellen platt gedrückt und machten den Eindruck eines cubischen, einschichtigen Epithels. Wo sie in mehrfacher Lage vorhanden waren, zeigten sie oft enorme Grösse. Nach dem Innenraum zu folgte anf diese Schicht häufig eine verschieden breite, von. Blut durchsetzte Masse, der sich dann eine schmale Schicht von Spindel- und Rundzellen mit starkem Blutpigmentgehalt ansehloss. Erst diese berührte den eigentlichen Cysteninhalt. Häufig bildete aber auch die erwähnte 
äussere Bindegewebsschicht die innerste Lage. Sehr oft erstreckten sich zungenförmige Ausläufer der grossen Zellen in das Ovarialstroma hinein. Ausserdem begegnete man diesen Zellen inselartig über das ganze Ovarialstroma zerstreut. Verfasser spricht die Cysten als Corpus-luteum-Cysten und die grossen Zellen, auch die herdweis im Ovarialstroma liegenden, als Luteïnzellen an, will aber nicht entscheiden, ob es sich bei letzteren um mangelhaft zurückgebildete Reste ehemaliger corpora lutea handelt, oder ob hier eine selbstständige, enorme Wucherung der Luteïnzellen vorliegt. Die an der Oberfäche liegenden Excrescenzen waren in ihren obersten Schichten aus Spindel- und Rundzellen zusammengesetzt. Nach dem Ovarium zo folgte dann eine zahlreiche junge Capillaren zeigende Schicht. An einzelnen Stellen sah man breite Züge von Luteinzellen bis unmittelbar an die Oberfläche des Ovariums ziehen und bier in. der Peripherie der Excrescenzen enden. Es gewann den Anschein, als ob hier Corpus-luteum-Cysten die Oberfläche des Ovariums durchbrochen batten, and es dann durch den Reiz des ausgetretenen Inhalts oder der noch weiter gewucherten Lutë̈nzellen zu einer circumscripten Entzündung gekammen war.

Schaller und Pförringer (21) berichten sehr genau über die gefundenen Veränderungen der Ovarien bei einem Fall von Blasenmole. Der rechte Eierstock war in einen knapp faustgrossen Tumor verwandelt. Seine Oberfläche war grobknollig, mit Höckern von Hasehnuss- bis Taubeneigrösse besetzt. Im Centrum war der Tumor von derbfaseriger, fester Beschaffenheit und solide, doch fanden sich schon hier zwei hanfkorn- bezügl. erbsengrosse cystische Gebilde mit orangegelbem Inhalt... Manche der Cysten, aus denen der Tumor zusammen gesetzt war, und zwar meist die kleineren, enthielten häufig frische oder ältere Blutmassen. Bei anderen war der Inhalt gelblich bis gelb-weisslich, orangegelb bis braunroth. An keiner Stelle standen die Cysten mit einander in Verbindung. Theilweise zeigte die Cystenwandung ein rauhes, zottjges Aussehen: Die Zahl der Cysten war ausserordentlich gross.

Mikroskopisch zeigte weitaus die grösste Zahl der Cysten folgendes Aussehen: Die Wand bestand aus zwei Schichten, einer äusseren, aus kernreichem, festerem oder lockerem Bindegewebe; und einer inneren aus einer vielschichtigen Lage von grossen, bald cubischen, bald runden, bald plattenepithelähnlichen Zellen mit grossem, schön sich tingirendem Kern und diffus sich färbendem Protoplasma. Diese Zellen lagen in Zügen oder Strängen ange- 
ordnet, zwischen welche sich zablreiche von den Gefüssen der äusseren Schicht andringende Capillaren einschoben. An der Grenze von Cystenwand und -inhalt sah man Zweierlei. Entweder die Zellen lockerten sich in ihrem Verband, sie wurden grösser, polymorph, mit längeren Ausläufern versehen; manchmal erschienen sie gequollen, rundlich, mit zahlreichen Fetttröpfchen erfüllt, während die Zellgrenzen undeutlich wurden, und die Kerne sich schwächer färbten. Endlich zerfielen die innersten Schichten in einen amorphen Detritus. Oder es wurden die Zellmassen getrennt von dem Cysteninhalt durch eine dünne Lage feinfaserigen Bindegewebes. Es hatte den Anschein, als ob von den jene Zellmassen durchziehenden Capillaren solide Sprossen getrieben würden. In dieser dünnen Bindegewebslage traf man häufig auf braune, eckige Pigmentkörnehen. In der Regel verlief die Innenfläche der Cystenwand nicht glatt, sondern wellig. Auch Ansammlungen von ein-oder mehrkernigen Rundzellen fanden sich in vereinzelten Cysten. An manchen Stellen drangen die Zellmassen, ohne von einer fibrösen Schicht begrenzt $z u$ sein, weit in das Ovarialstroma hinein, und es konnte so zwischen zwei benachbarten Cysten zu.einer Verschmelzung ihrer Zellmassen kommen. Einmal fand sich ein grosser Graafscher Follikel fast allseitig von den Zellmassen umgeben, seine Theca war überall erhalten. Aber auch unabhängig von den eben beschriebenen Bildungen und mit ihnen in keinem Zusammenhangstehend, fanden sich Ansammlungen jener Zellen mitten im Ovarialstroma, bald in Form von rundlichen Massen, die durch Bindegewebsstreifen in verschieden starke Nester getheilt waren, bald in Form von lang sich hinziehenden Strängen. Zuweilen lagen die Zellen in directer Umgebung grösserer Lymphbahnen. Die ,Verfasser sprechen diese Cysten als Corpus-luteum-Cysten an, von denen ein Theil sich in carcinomatöser Degeneration befindet, indem sie den Zellen eine starke Proliferationsfähigkeit und ein selbstständiges Wachsthum zusprechen.

Als letate führe ich die sehr gute und ausfübrliche Arbeit von Stoeckel (27) an. Bei einem Fall von Blasenmole waren die beiden Eierstöcke in fast mannskopfgrosse llumoren umgewandelt. Das makroskopische Bild derselben entsprach dem eines multiloculären Kystoms. Die Cysten waren äusserst zahlreich und von verschiedener Grösse. Die Cysteninnenfläche war leicht gewellt, zuweilen deutlich gefaltet, nur ausnahmsweise ganz glatt. Ihre Farbe wechselte zwischen einem röthlichen Weiss und einem dunkeln 
Rostbraun. Der mikroskopische Befund war folgender: Das ganze Tumorgewebe zeigte sich stark ödematös durchtränkt. Im Ovarialstroma lagen feine hyaline Streifen und Massen, als Ueberreste von corpora albicantia, und in deren Umgebung Luteinzellen. Ausserdem waren letztere auch über das ganze Ovarialstroma zerstreut, einzeln, in zusammenhängenden oder unterbrochenen Zügen, oder in kleineren Haufen. Die Wand der Cysten bestand aus vier verschiedenen Schichten. Von aussen gerechnet traf man zuerst auf einen schmalen Streifen derbfaserigen, verdichteten Bindegewebes, der gewissermaassen eine Kapsel der Cyste und eine Abgrenzung gegen das Stroma ovarii bildete. Als zweite Schicht fügte sich eine zweite Lage von Bindegewebe an, die sich durch einen grossen Zell- und Gefässreichthum auszeichnete und dementsprechend lockeres Gefüge hatte. Als dritte Schicht folgte eine vielreihige Lage von sebr auffallenden, pallisadenartig neben einander liegenden Zellen, deren Verlaufsrichtung eine zur Cystenwand senkrechte, radiäre war. Das Auffallendste an diesen Zellen war ihre Grösse. Zwischen diesen grossen, blasigen Zellen lag ein aus der zweiten Bindegewebslage stammendes Gerüst, welches in die ersten Reihen der grosszelligen Schicht hineinzog, um sich dann allmählich zu verlieren. Dieses Gerüst bestand aus feinen Bindegewebsfibrillen und zahlreichen Capillaren. Als vierte Schicht und eigentliche Auskleidung der Cyste fand sich ein der dritten Schicht aufliegender, membranartiger Belag von Bindegewebe, Blut oder Fibrinniederschlägen. Verfasser spricht diese Cysten als Corpusluteum-Cysten an. Andere Cysten zeigten aber auffallende Abweichungen von dem eben angegebenen Bau. Dieselben waren folgende: Die eine oder die andere der ersten beiden Schichten fehlte. Oder Theca- und Luteïnzellen gingen in einander über. Oder aber die Luteïnzellen zogen schrankenlos in das Ovarialstroma hinein. Dies sieht Verfasser nicht für ein bösartiges Wachsthum an. Als Grund dafür glaubt er gefunden zu haben, dass durch das Hineinwachsen von Blutgefässen in die Luteïnzellenschicht Zellen derselben abgesprengt werden. Er hält diese Erscheinung also nicht für eine Zellwucherung, sondern nur für eine Zellverlagerung.

Eine weitere Abweichung von dem normalen Typus bestand darin, dass theilweise die Luteïzellen direct an den Cysteninhalt heranreichten. In einer Cyste fand er auf der Luteïnschicht noch Granulosazellen. Ausser dieser Art von Cysten fand er auch solche, 
und zwar in noch grösserer Anzahl, die er als Retentionseysten der Follikel anspricht. Eine dritte Art von Hohlräumen, die einen Endothelbelag hatten, hält er für stark ektasirte Lymphräume und Lymphspalten. In dem anderen Ovarium fand er ein grösseres Corpus luteum von normalem Bau und ein kleineres, wo er in noch höherem Maasse, als bei den oben gesehilderten Cysten die Absprengung von Luteïzellen constatiren konnte.

Was nun die von mir untersuchten Fälle betrifft, so standen mir von 7 Fällen von syncytialen. Tumoren und von einem Fall von Blasenmole die bezüglichen Ovarien zur Verfügung. Ueber den makroskopischen Befund derselben zu berichten, ist mir leider nur bei vier der ersteren und bei der Blasenmole möglich, da sich nur diese Präparate in der Sammlung des pathologischen Institutes des Friedrichstadt-Krankenhauses zu Dresden befanden. Bei den übrigen Fällen musste ich mich mit der mikroskopischen Untersuchung von Stücken begnügen, die aus den bezüglichen Ovarien excidirt und in Paraffin eingebettet vorhanden waren. Herr OberMed.-Rath Dr. Schmorl hatte die Liebenswürdigkeit, mir dieselben zur Verfügung zu stellen.

Für die mikroskopische Untersuchung wurden die angefertigten Schnitte theils mit Hämatoxylin-Eosin, theils mit van Gieson'seher Lösung gefärbt. Speciell letztere Methode lieferte sehr schöne und instructive Bilder.

Im Interesse der Uebersichtlichkeit will ich zuerst den makroskopischen Befund jedes der mir zur Verfügung stehenden Fälle einzeln angeben, und dann, um Wiederholungen zu vermeiden, den mikroskopischen Befund zusammenfassend behandeln, da derselbe bei allen Fällen fast völlig derselbe ist.

\section{Fall I.}

Es handelt sich um einen syncytialen Tumor des Uterus, äber den Fiedler (4) schon berichtet hat. Die beiden Ovarien sind in grosse Tumoren umgewandelt und bieten im Grossen und Ganzen das typische Bild eines multiloculären Kystoms dar. In Folge des langen Aufenthaltes in der Conservirungsflüssigkeit sind sie stark geschrumpft und haben auch dadurch an Volumen sehr eingebüsst, dass mehrere grössere Cysten eröffnet sind, und ihr Inhalt abgelanfen ist. Trotzdem haben beide noch die Grösse und die annähernde Gestalt eines frischen Gehirns einer erwachsenen Person. Sehätzungsweise müssen sie in frisehem Zustande ungefähr Manns- 
kopfgrösse gehabt haben. Sie stehen durch einen dünnen Stiel, der von der Tube und der Mesosalpinx gebildet wird, mit dem Uterus in Zusammenhang. Die Tuben selbst, die sonst normal sind, ziehen in einer Länge von ca. $12 \mathrm{~cm}$ über die Tumoren hinweg und sind fest mit ihnen verwachsen. Die Oberfläche der Tumoren ist glänzend, von vielfachen, sich nach allen Richtungen durchkreuzenden, meist ziemlich flachen Furchen durchzogen. Makroskopisch können nirgends Reste von Ovarialgewebe festgestellt werden.

Der rechte Tumor besteht aus zwei gut faustgrossen, ungefähr sechs wallnussgrossen und einer Unzahl kleinerer Cysten von Haselnuss- bis Stecknadelkopfgrösse. Der Aufbau derselben ist überall gleich. Die Innenfläche der Cysten ist nicht glatt, sondern hat einen mehr sammtartigen, rauhen Charakter, was, soweit es makroskopisch festgestellt werden kann, auf einer ganz feinen Faltenbildung beruht. Die Cystenwandungen, welche durchschnittlich eine Dicke von $0,7-1,5 \mathrm{~mm}$ haben, sind nieht, wie es zumeist bei den gewöhnlichen multiloculären Kystomen der Fall ist, durchscheinend, sondern haben einen mehr lederartigen Charakter. Bei genauerer Betrachtung bemerkt man, dass sie aus zwei deutlich von einander getrennten Schichten bestehen. Innen liegt eine feine Membran, die in ihrer ganzen Dicke eine gelb- bis dunkelbräunliche Färbung zeigt, welche trotz der Alkoholbehandlung deutlich hervortritt. Hin und wieder finden sich ganz feine, flache Auflagerungen auf ibr von Sandkorn- bis Hirsekorngrösse. Auch sie zeigen eine ausgesprochen gelblichbranne Farbe. Entfernt man diese Schicht, indem man sie von ihrer Unterlage abzieht, was unschwer gelingt, so bleibt die zweite - äussere - Schicht zurück, die ein sehr viel derberes Gefüge besitzt und bläulich durchscheinend ist. Der Cysteninhalt ist - so weit noch vorhanden - in eine weiche, stärkekleisterähnliche Masse von gelblich-weisser Farbe umgewandelt, welche hin und wieder einen mehr bräunlichen Ton annimmt. Ausgesprochene Blutungen sind in ihr nirgends bemerkbar. Diese Massen haften der Cysteninnenfläche theilweise ziemlich fest an. Sucht man sie zu entfernen, so bleiben oft mehr oder weniger geringe Mengen davon in dünner Lage auf der Innenwand haften. Im Gegensatz zu dem oben angegebenen Dickendurchmesser der Cystenwandungen finden sich hin und wieder solche, welche eine sehr viel bedeutendere Stärke zeigen - bis zu $1 / 2-3 / 4 \mathrm{~cm}$. In diesen bemerkt man hauptsäch- 
lich da, wo mehrere Cysten zusammenstossen, aber auch in der Trennungswand nur zweier Cysten fast bis an die Oberfläche reichende Herde, welche nicht scharf gegen die Umgebung abgegrenzt sind, sondern allmälig in dieselbe übergehen. Ihre Farbe ist braun, und zwar in der Weise, dass im Innern des Herdes das Gewebe fast dunkelbraun ist, während es nach der Peripherie zu allmälig heller wird, und schliesslich die gelb-bläuliche Farbe des umliegenden Gewebes da ist, ohne dass man eine scharfe Trennungslinie zwischen beiden zu ziehen vermag. Die Gestalt dieser Herde ist eine verschiedene, die wohl hauptsächlich von dem Innendruck der anliegenden Cysten, sowie dem Modus der Aneinanderlagerung derselben abbängig ist. Bald sind sie rund, bald vieleckig (speciell an den Stellen, wo mehrere Cysten zusammenstossen), bald in die Länge gezogen, bandartig (hauptsächlich da, wo sie in der Trennungswand nur zweier Cysten liegen). Die Grösse der Herde schwankt zwischen Linsen- bis Bohnengrösse; selten finden sich kleinere. Sie sind von ziemlich weicher, bröckliger Beschaffenheit, ohne irgend welche feinere Zeichnung im Innern. An einer Stelle gleich unterhalb der Oberfläche des Tumors findet sich ein ähnliches Gebilde, welches sich jedoch durch Mancherlei von den eben beschriebenen unterscheidet. Vor Allem ist es viel grösser - gut haselnussgross. Sodann ist es scharf gegen die Umgebung abgegrenzt und schliesslich lässt es eine deutliche Zeichnung sowie Gruppirung in verschiedene Theile erkennen. An seiner Peripherie wird es von einer Schicht gebildet, die eine Dicke von $1-1 \frac{1}{2} \mathrm{~mm}$ hat, gelblich-braun gefärbt ist und einen welligen Verlauf zeigt, so dass auch das ganze Gebilde selbst nach aussen hin durch eine wellige Linie abgegrenzt ist. Hierauf folgt nach innen ein $1 / 2 \mathrm{~mm}$ breiter Streifen, der eine exquisit dunkelbraune Färbung zeigt. An ihn schliesst sich der eigentliche Kern des Herdes an, welcher wieder heller gefärbt ist. Im Innern dieses findet sich ein Hohlraum von gut Hirsekorngrösse. Seine Innenfläche, welche von der Substanz des Kernes gebildet wird, ist fein granulirt, wie bestäubt. Welcher Art der Inhalt dieses Hohlraums war, lässt sich nicht mehr feststellen. Auch dieser Herd ist von ziemlich weicher, markiger Beschaffenheit. Nach dem makroskopischen Aussehen darf man wohl sicher annehmen, dass man hier ein Corpus luteum verum vor sich hat. In nächster Umgebung dieses Gebildes liegen zwei Cysten von Erbsengrösse, welche nur dadurch von dem Bau der übrigen 
Cysten abweichen, dass die sie innen auskleidende Membran hier auf $2-3 \mathrm{~mm}$ verdickt und mehr dunkelbraun gefärbt ist. Thre nach innen gerichtete Fältelung tritt sehr viel deutlicher zu Tage, als bei den übrigen Cysten.

Der linke Tumor zeigt genau denselben Bau wie der rechte. Auch bei ihm prävaliren zwei gut apfelgrosse und mehrere wallnussgrosse Cysten. Der übrige Theil des Tumors wird von kleineren Cysten gebildet. Diese alle zeigen denselben Aufbau, wie er schon oben bei dem rechten Tumor beschrieben war. Den einzigen Unterschied bildet das Fehlen eines Corpus luteum.

F all II.

Es handelt sich um einen Eall von Scheidenmetastase eines syncytialen Tumors, über den Schmorl (23) schon berichtet hat. Der Uterus ist frei von Geschwulstmasse. Das rechte Ovarium ist von normaler Grösse und Gestalt, compact, ohne makroskopisch bemerkbare Cysten. Es enthält ein Corpus luteum verum ohne sichtbare Besonderheiten. Das linke Ovarium ist in einen Tumor von knapp Wallnussgrösse umgewandelt. Der mediale Theil desselben besteht aus typischem Ovarialgewebe, während der laterale von einer Cyste gebildet wird, die gut haselnussgross ist. Die Wandungen derselben sind durchsehnittlich $2 \mathrm{~mm}$ dick und werden aus drei deutlich von einander geschiedenen Schichten gebildet. Nach aussen zu bemerkt man eine feste, bläulich-weiss gefärbte Schicht, dann folgt nach innen zu eine zweite, welche mit der ersteren nur durch lockeres Bindegewebe verbunden ist und dieselbe Färbung zeigt, und schliesslich die innerste, welche in ihrer ganzen Dicke exquisit gelb-bräunlich gefärbt ist und auf ihrer Innenseite eine sammtartige Oberfläche darbietet, die nach allen Richtungen von ganz feinen, nur wenig tief einschneidenden Einsenkungen durchzogen wird. Da die Cyste eröftnet ist, können über den Inhalt derselben keine Angaben mehr gemacht werden. Nach dem lateralen Pol zu bildet dic Cystenwandung zugleich die Tumoroberfiäche; während sie medial an den übrig gebliebenen Theil des Ovarialgewebes stösst. In dieser Gegend sitzt der Tumoroberfläche eine etwa erbsengrosse Cyste auf, welche mit der grösseren in keinerlei Verbindung steht, sondern durch Ovarialgewebe völlig von ihr getrennt ist. Der Bau dieser Cyste stimmt makroskopisch bis in die kleinsten Einzelheiten mit dem der grossen überein. Die normalen Tuben verlaufen frei über die Ovarien hinweg und stehen in keiner pathologischen Verbindung mit denselben. 


\section{Fall III.}

Es handelt sich um einen durch Operation gewonnenen Uterus, der nur wenig vergrössert ist. In der Vorderwand, sie nur theilweise durchsetzend, findet sich ein nicht ganz scharf gegen die Umgebung abgegrenzter Knoten von gut Haselnussgrösse, der als syncylialer Tumor angosprochen werden muss. Nach dem Uterusinnern zu zeigt er eine unregelmässige, höckerige Oberffäche und ist von ausgedehnten Blutungen durchsetzt. Die Ovarien sind etwa mandarinengross. Ihre Oberfläche ist flach höckerig, schwach weiss gefärbt. Die flachen Höcker, welche von einander durch seichte Furchen getrennt sind, entsprechen Cysten, welche an der Oberfläche des Ovariums liegen und ebenso auch das Ovarium in seiner ganzen Ilasse durchsetzen. Sie sind erbsen- bis bohnengross, dünnwandig, und platten sich, da, wo sie sich berühren, gegenseitig ab. Sie werden von einer zarten, mattglänzenden Membran ausgekleidet und enthalten dünnflüssigen, serösen Inhalt, in dem vereinzelte, ziemlich grosse, kubische Zellen mit feinkörnjgem Protoplasma und kleinem Kern enthalten sind.

$$
\text { Fall IV. }
$$

Es handelt sich um einen Fall von syncytialem Tumor, über den Schmorl (22) schon berichtet hat. Der Lterus ist völlig durch die Tumormasse substituirt. Von den Ovarien ist an dem Präparate nichts mehr zu erkennen. (Zur mikroskopischen Untersuchung standen mir von denselben in Paraffin eingebettete Stücke zur. Verfügung.)

$$
\text { Fall V, VI, VII. }
$$

Von diesen Fällen von syncytialen Tumoren konnte ich nur in Paraffin eingebettete Stücke der Ovarien mikroskopisch untersuchen, da die bezüglichen Präparate sich leider nicht in der Sammlung befanden.

\section{Fall VIII.}

Es handelt sich hier nicht, wie in den bisherigen Fällen, um einen syneytialen Tumor, sondern um eine Blasenmole. Der makroskopische Befund des Präparates ist folgender: Ein gravider Uterus von der Grösse, wie sie etwa dem 8.-9. Monat normaler Schwangerschaft entspricht, zeigt eine Wandstärke von $1 / 2-3 / 4 \mathrm{~cm}$ und ist im Innern völlig von einer typischen Blasenmole ausgefüllt. Beide Ovarien sind in gut faustgrosse Tumoren umgewandelt. Die Tuben, ca. $10 \mathrm{~cm}$ lang, laufen frei über dieselben hinweg und bilden zu- 
sanmen mit der Mesosalpinx jeder Seite dünne Stiele, dureh welche die Ovarialtumoren mit, dem Uterus zusammenhängen. Die Oberfläche derselben ist glänzend, von vielen seichten Einsenkungen durchzogen. Makroskopisch geben beide Tumoren das typische Bild eines multiloculären Kystoms. Die Wandungen der einzelnen Cysten sind zum Teil dünn, durchscheinend und von bläulich- bis rothgrauer Färbung. Theilweise aber wird die zwei oder mehrere Cysten trennende Wand aus einer breiteren (oft bis $1 / 2-3 / 4 \mathrm{~cm}$ dicken) Gewebsmasse gebildet, welche ein sulzig-ödematöses Aussehen zeigt. Auf einer die Tumoren in ihrer ganzen Breite durchsetzenden Schnittläche findet man in diesen Wandungen an mehreren Stellen eigenartige Herde von verschiedenartiger Grösse und Gestalt. Die Farbe derselben ist exquisit gelb (nicht wie in Fall I. bräunlich). Abgesehen von dieser Differenz zeichnen sie sich auch von den oben erwähnten Herden dadurch aus, dass sje ziemlich scharf gegen die Umgebung abgegrenzt sind, aus der Schnittfläche etwas hervorspringen und ein etwas festeres Gefüge zu haben scheinen. Eine feinere Strueturzeichnung vermögen aber auch sie nicht aufzuweisen, sondern sie haben eine mehr homogene, markartjge Beschaffenheit. Was die Grösse der Cysten betrifft, so sind sie hierin völlig verschieden - von Wallnuss- bis Hirsekorngrösse. Irgend eine Regelmässigkeit in der Anordnung derselben lässt sich nirgends erkennen. Die Auskleidung der Cysten wird auch hier, ebenso wie in den oben beschriebenen Fällen von einer gelb-bräunlichen Membran gebildet, welche Faltenbildung aufwcist und auf der Innenfläche einen sammetartigen Charakter bat. Der Inhalt der Cysten stellt (nach der Alkoholbehandlung) eine sulzige, trübe, an Farbe und Consisteuz stärkekleisterähnliche Masse dar, welche ziemlich fest der Cystenwand anhaftet. Irgend welche Blutungen in diese hinein sind nirgends zu constatiren. Ein Corpus luteum verum ist in keinem der beiden Tumoren zu finden; ebenso ist makroskopiseh nirgends Ovarialgewebe bemerkbar.

Will man mit kurzen Worten die oben gefundenen Verhältnisse charakterisiren, so kann man sagen, dass es im Grossen und Ganzen den Eindruck macht, als ob man gewöhnliche multiloculäre Kystome vor sich hat, bei denen der Innenwand jeder Cyste noch eine feine, gelbbräunlich gefärbte Membran aufliegt.

Im Folgenden will ich nun über die Befunde berichten, die sich bei der mikroskopischen Untersuchung der soeben geschilderten 
Ovarialtumoren ergeben haben. Ohne die Individualität jedes einzelnen Tumors zu beeinträchtigen, kann dies zusammenfassend geschehen, da die Ergebnisse bei allen fast bis in die kleinsten Einzelheiten dieselben sind, und somit bei Schilderung jedes Falles für sich nur Wiederholungen die Folge sein würden.

Die Oberfläche der Tumoren wird yon einer, mit der Tunica albuginca des Ovariums in Aufbau und sonstigen Verbältnissen völlig übereinstimmenden Schicht kernarmen Bindegewebes gebildet, welches aus langen, welligen Fibrillen besteht, die parallel der Oberfläche verlaufen und eng an einander gelagert sind. Die Dicke dieser Schicht ist ungefähr dieselbe, wie die der Tunica albuginea normaler Ovarien; hin und wieder findet man sie dünner, manchmal sogar bis auf wenige, neben einander liegende Fasern reducirt; selten ist sie dirker als normal. Eigentlich sollte man dieser Schicht aufliegend eine Lage Keimepithel erwarten. Dies ist jedoch nur ganz selten in kleinen, mehr oder weniger tiefen Ausbuchtungen der Oberfläche der Fall; sonst ist das Keimepithel uberall verloren gegangen.

Das die eigentliche Grundlage der Cystenwandungen bildende Bindegewebe, welches naturgemäss unter der eben geschilderten Schicht liegt, ist ziemlich kernreich und bestcht aus mässig langen, sich nachallen Richtungen durchflechtenden Fibrillen, die oft spindelförmige Gestalt haben. Die intensiv gefürbten Kerne derselben sind rundlich, oft aber auch mehr länglich geformt. Das ganze Gewebe erinnert sehr an typisches Ovarialstroma. Grössere Anhäufungen desselben, sodass man von einem Restiren von Ovarialgewebe reden könnte, finden sich nirgends. Die Vertheilung des soeben geschilderten Gewebes ist vielmehr die, dass es in Gestalt mehr oder weniger schmaler Streifen entweder unter der oberfächlichen Albuginea oder in der Wandung zweier oder mehrerer an einander stossender Cysten liegt. Die Dicke dieser Schicht, die naturgemäss von der Dicke der Cystenwandungen abhängt, schwankt durchschnittlich zwischen $0,2-4,5 \mathrm{~mm}$. Nur an wenigen Stellen erreicht sie einen Durchmesser bis zu $1 \mathrm{~cm}$. In den dünnsten Cystenwandungen findet sich entweder überhaupt kein derartiges Bindegewebe, oder aber es sind nur einige wenige Fibrillen davon vorhanden, die man nur durch ihren Zusammenhang mit dickeren Sehichten von Orarialstroma als diesem zugehörig zu erkennen vermag. Die Anordnung der einzelnen Bindegewebsfasern, speciell in dïnneren Wandungen, ist oft die, dass dieselben concentrisch 
zum Mittelpunkte der anliegenden Cysten verlaufen. Sehr vielfach zeigt das Bindegewebe einen aufgequollenen, ödematösen Character. Der Grad desselben ist ein sehr verschiedener. Manchmal ist es nur ganz gering, sodass die Bindegewebszellen nur wenig von einander entlernt liegen. An anderen Stellen dagegen ist es in hohen Maasse ausgesprochen, sodass zwischen den einzelnen Bindegewebsfibrillen ein leerer Raum liegt, der mehrfach an Breite dem 4-5 fachen einer Bindegewebszelle entspricht. Manchmal ist man sogar zweifelhaft, ob es sich nur um ein oedematöses Auseinanderdrängen der Zellen handelt, oder um Lymphspalten oder Lymphräume. Auch diese selbst finden sich zahlreich in dem Bindegewebe und durchsetzen dasselbe oftmals in ausgedehnter Weise; ebenso wie auch die Vertheilung der Blutgefässe streckenweis eine geradezu ausserordentliche sein kann. Nur ganz selten fnden sich in das bindegewebige Stroma Primärfollikel eingelagert und ebenso wenig normale ausgebildete Follikel. Oefters dagegen begegnet man solchen, die in Degeneration begriffen sind. Zumeist ist die membrana granulosa von der Wandung abgelöst, und das Ovulum zeigt keine scharfen Conturen. Auch corpora candicantia, wenigstens solche von normalem, typischem Bau, sind nur in geringer Zahl vorhanden. An den verschiedensten Stellen finden sich in dem Bindegewebe Haufen verschiedenartiger Grösse und Gestalt, die aus grossen, bläschenförmigen Zellen bestehen. Wir wollen hierauf später zu sprechen kommen.

Wenden wir uns jetzt der eigentlichen Cystenauskleidung z $\mathrm{u}$, so fällt uns hier ein Theil derselben sofort in das Auge, nämlich ein versehiedensehichtiges Lager grosser Zellen, deren Charakter ich erst genauer beschreiben möchte, ehe ich auf die Gesammt-Structur der Cystenwandungen eingehe. Es handelt sich um grosse Zellen von verschiedener Gestalt. Bald sind sie rund (und dies scheint der Normalzustand zu sein), bald sind sie mehr eylindrisch oder cubisch. Auch pflasterepithelähnlich an einander gelegte finden sich. Vielfach sind sie mit verschieden langen, schmalen oder mehr plumpen Ausläufern versehen. Ihre Grösse schwankt zwischen $15-20 \mu$ bei einigermaassen runder Gestalt. Sind die Ausläufer lang, so können die Zellen einen Durchmesser von $24-30 \mu$ erreichen. Diese verschiedenen Formen sind abhängig theils von dem Druck des Cysteninhalts, theils von dem versehiedenartigen Modus der Aneinanderlagerung der Zellen. Speciell ist dies in Bezug auf die Ausläufer der Fall, die in die Zwischenräume der anliegenden Zellen hinein- 
geschoben sind. Was die feinere Structur der Zellen betrifft, so ist das Protoplasma blass, bei Eosinfärbung ziemlich schwach gefärbt und hat grösstentheils in kolge eines darin abgelagerten, äusserst feinen, mit dem Mikroskop kaum differenzirbaren Pigments einen gelblichen Ton. Zumeist ist es ziemlich klar, nur hin und wieder etwas trübe. Der Kern ist gross, bläschenförmig, von meist runder Gestalt. Ist die Form der Zelle stark verändert, so kann er auch dementsprechend eine mehr eckige oder längliche Gestalt annehmen. Seine Färbbarkeit ist eine mässig intensive. Sie lässt jedoch Kernstructur and ein Kernkörperchen deutlich erkennen. Grösstentheils liegt der Kern in der Mitte der Zelle, nur selten ist er nach der einen oder der anderen Seite etwas verlagert. Fast durchweg enthält jede Zelle nur einen Kern. Ich sah nur wenige Zellen mit zwei, keine mit mehreren. Sucht man ein Vergleichsobject für diese Zellen, so wird man sofort an die Luteïnzellen erinnert, denen sie in ihrem ganzen Aufbau, Färbbarkeit etc. ausserordentlich gleichen. Allerdings erreichen sie nicht immer die Grösse derselben, doch beruht dies wohl nur aut dem Druck, den der Cysteninhalt auf sie ausübt. Denn überall da, wo sie frei und nicht unter diesem stehend zur Beobachtung kommen, kann eine frappirende Uebereinstimmung zwischen ihnen und den Luteinzellen auch nach dieser Richtung hin nicht abgeleugnet werden.

Gehen wir nun zu dem Bilde über, das die Cystenwandung in ihrer Gesammtheit darbietet, so sehen wir, dass dieselbe folgende Zusammensetzung hat. Zuerst schliesst sich von aussen her an das Ovarialstroma eine schmale Schicht von Bindegewebe an, welches diesem ähnlich gebaut, nur dichter gefügt und derbfaseriger ist. Dann folgt die II. Schicht, die ebenfalls bindegewebiger Natur ist, nur ein mehr lockeres Gefüge hat, sehr reich an Kernen ist und von vielen Blutgefässen durchzogen wird. Sie besteht aus kurzen, feinen Bindegewebsfibrillen, die anscheinend dureh ein geringes Oedem etwas auseinander gedrängt sind. Hieran schliesst sich dann nach innen zu die III. Schicht, welche sich aus den grossen, soeben gesehilderten Zellen zusammensetzt. Keineswegs jedoch ist diese Schichtenbildung immer so deutlich ausgesprochen, wie eben geschildert. Oft geht die eine Schicht in die andere über, ohne dass man eine scharfe Trennungslinie zwischen ihnen zu ziehen vermag. Dies gilt nicht bloss von Schicht I und II, sondern, wenn auch seltener, von II und III. In letzterem Falle erscheinen dann die Zellen der II. Schicht mehr aufgequollen, so dass cine Differenzirung: 
derselben von den grossen Zellen der III. Schicht nicht immer durchführbar ist. Die Mächtigkeit der III. Schicht ist eine sehr verschiedene. Hin und wieder liegt nur eine Zelle neben der anderen. Dann finden sich wieder Stellen, wo die Zellen in dicker Lage, oft zu 8-10 übereinander geschichtet sind. Ja, an einzelnen, eircumscripten Stellen ballen sie sich zu grossen, kugeligen, in das Cystenlumen hineinragenden Haufen zusammen. Ist dies sehr ausgesprochen der Fall, so haben wir die oben (bei Fall I) beschriebenen, makroskopisch sichtbaren, flachen Auflagerungen auf der Cysteninnenfläche vor uns. Hin und wieder nehmen diese Haufenbildungen Gestalten an, die sehr an carcinomatöse Entartung eines papillären Kystoms erinnern. Die Cysteninnenfläche ist in der nächsten Umgebung derartiger Stellen von einem melirschichtigen Lager von Luteïnzellen gebildet, das dann plötzlich stark an Vächtigkeit zunimmt, indem die Luteïnzellenhaufen in baumartiger Verzweigung in das Cystenlumen hineinragen.

Was nun die Form dieser Luteinzellen betrifft, so ähnelt das Bild da, wo sie ein einschichtiges Lager bilden, sehr dem eines cubischen oder cylindrischen Epithels. Dieser Unterschied in der Form jst sowohl von der Art, wie die Zellen sich an einander lagern, abhängig, vor 'Allem aber von dem Cysteninnendruck, der auf ihnen lastet. Ist nämlich speciell letzterer gering, so haben wir mehr eylindrische Zellen vor uns, ist or aber gross, so sind die Zellen mehr platt. Da, wo diese in mehrschichtiger Lage angeordnet sind, ist ihre Gestalt ebenfalls von den oben erwähnten Momenten abbängig. Sind letztere gering, so macht das Zelllager den Eindruck, als wären würfelig oder polyëdrisch gebante Zellen an einander gefügt. Ist speciell aber der Cysteninnendruck ein grösserer, so liegen die Zellen in einer Art an einander, die man mit der des Pflasterepithels vergleichen könnte. Am nächsten der Cysteninnenfläche sind die Zellen flach, platt, mit ihrer Längsachse concentrisch angeorduet, indem aush ihr Kern eine mehr längliche Form besitzt. Nach aussen zu werden sie dann allmählich höher, um schliesslich einen völlig cubischen Charakter anzunehmen. Da, wo sie, wie oben eryähnt, in grossen Haufen zusammen liegen, bietet sich wieder ein anderes Bild dar, indem es hier den Eindruck macht, als ob die einzelnen Zellen durch ein locales Oedem von einander getreint worden wären. Keineswegs jedoch darf man annehmen, dass in einer Cyste die Mächtigkeit des Luteïnzellenlagers immer die gleiche ist. Sie unterliegt vielmehr oft in ein und 
derselben ganz bedeutenden Schwankungen. Manchmal ist das Zelllager mehrere Gesichtsfelder hindurch einsehichtig, dann folgt ganz plötzlich ein drei- bis vierschichtiges, um vielleicht noch in demselben Gesichtsfelde auf eine Breite von nur zwei Zellen herabzusinken oder sich zu einem dichten Haufen vielschichtiger Zellen zusammen zu ballen. Irgend eine Gesetzmässigkeit in der Anordnung der Zellen kann somit nirgends erkannt werden. Dies schliesst jedoch wiederum nicht aus, dass in einzelnen Cysten das Zellenlager an Mächtigkeit nur ganz geringen Schwankungen unterliegt, dass z. B. die Zahl der über einander gelagerten Zellen nio fünf übersteigt und nie unter drei heruntergeht.

Nach dem bisher Geschilderten dürfte man annehmen, dass immer direct Zelle an Zelle stösst, ohne dass irgend ein Zwischengewebe vorhanden ist. Dies ist jedoch nur theilweise der Fall. Meistens findet man, dass von der Schicht I oder II der Cystenauskleidung mehr oder weniger breite, meist aber sehr feine Bündel von Bindegewebe, die von zarten Capillaren begleitet sind, sich zwischen die Luteinzellen hineinschieben und sich hier nach allen Richtungen verzweigen. In ihrer ganzen Breite durchsetzen sie die Zellschicht nur selten, meist dringen sie nur bis ungefähr zur Hälfte derselben vor.

Mehrfach kommt es auch vor, speciell da, wo das Luteinzellenlager nur aus einer oder wenigen Lagen besteht, dass zumeist auf kürzere, selten auf längere Strecken die Cystenauskleidung völlig der Luteïnschicht entbehrt, und ihre II. Schicht direct die Cysteninnenfläche bildet. Hauptsächlich ist dies bei grössere]\} Cysten der Fall, wohl als ein Ausdruck des gesteigerten Innendruckes. Zumeist sind dann die Fasern der II. Schicht concentrisch angeordnet, ihre Oberfläche besitzt ein welliges Gefüge und ihr Kernreichthum ist ein geringer.

In ungefähr der Hälfte der Fälle wird die Cysteninnentläche, wie eben geschildert, von der Luteïnschicht gebildet. Andrerseits können ihr nach innen zu Gebilde verschiedener Art aufliegen. Entweder ist es Cysteninhalt, in den vereinzelte abgesprengte Luteïnzellen und hin und wieder rothe Blutkörperchen in geringer Menge eingeschlossen sind. Oder aber ein feines homogenes Band, das der Luteinschicht in der ganzen Circumferenz der Cyste aufgelagert ist. Allerdings ist es hin und wieder von derselben abgehoben und liegt frei im Cystenlumen, was aber wohl sicher nicht den natürlichen Verhältnissen entspricht. Des Weiteren 
finden sich oft auf der Luteïnschicht Niederschläge von Fibrin in wechselnder Mächtigkeit. In dasselbe sind fast immer rothe Blutkörperchen verschieden dicht eingeschlossen. Manchmal überwiegen dieselben sogar an Zahl derart, dass von dem Fibrin kaum etwas zu sehen ist, und man fast den Eindruck erhält, als läge ein verschieden mächtiges Band von rothen Blutkörperchen der Luteïnschicht auf. Vielfach sind die Blutkörperchen nicht gut erhalten, sondern in Zerfall begriffen, so dass nur noch Schollen davon vorhanden sind und daneben, in oft selır reichlicher Menge, Blutpigment.

Entbehren jedoch diese Fibrinniederschläge jeglichen Einschlusses, so ist dasselbe fest gefïgt, liegt ziemlich gleichmässig breit der Luteinschicht auf und verleiht durch seine wellige Anordnung der Cysteninnenfläche ein dementsprechendes Gefüge.

Des Weiteren findet man manchmal der Luteïnschicht ein zumeist ziemlich schmales Band von Bindegewebe aufliegen, welches nur mässig kernreich ist und aus langfaserigen, oft deutlich gewellten Fibrillen besteht. Ist es jedoch breiter, so ist sein Gefüge zumeist lockerer und ähnelt in seiner Structur auffällig der Schicht II der Cystenauskleidung, sodass man genejgt ist, anzunehmen, dass es von dieser abstammt. Noch wahrscheinlicher wird diese Vermuthung durch folgende Beobachtung: Oben wurde erwähnt, dass sehr oft von der Schicht I oder II der Cystenauskleidung bindegewebige Züge mitsammt feinen Capillaren in die Luteinschicht hineinziehen und ungefähr in der Mitte derselben ihr Ende finden. Nun sieht man hin und wieder, wie diese Züge die Luteïnschicht in ihrer ganzen Breite durchsetzen und, sobald sie die Oberfläche derselben erreicht haben, scharf umbiegen, um sich auf sie aufzulegen. Diesen Vorgang kann man nun immer da beobachten, wo ein bindegewebiges Band die Luteïnschicht von dem Cystenlumen trennt. Nan darf daher wohl annehmen, dass dieses seine Entstehung dem eben geschilderten erhöhten Wucherungsprocess der Schicht I oder II verdankt. In einigen Cysten lag dieser bindegewebigen Schicht noch ein feines, homogenes Band auf von derselben Art, wie es oben schon als den Luteïnzellen anliegend geschildert wurde.

Wenn wir nun noch einmal kurz die Zusammensetzung der Cystemauskleidung recapituliren, so finden wir, dass dieselbe von aussen nach innen zu aus folgenden Schichten besteht. Zuerst kommen zwei Streifen ver- 
schiedenartigen Bindegewebos, die nieht immer deutlich von einander getrennt sind, dann die von feinen Bindegewebszägen und Capillaren durchzogene Luteïnzellenschicht. Dieser können nun noch entweder Niederschläge von Fibrin mit verschiedenartigem Einschluss oder Bindegewebe aufliegen, ausserdem auf diesem oder der Luteinschicht selbst noch ein feines homogenes Band.

Nachdem ich so nun den Aufbau der Cystenauskleidung geschildert habe, will ich jetzt auf die schon oben erwähnten Herde von eigenartigen, grossen, bläschenförmigen Zellen eingehen, die sich vielfach im bindegewebigen Stroma fanden. Was den feineren Aufbau dieser Zellen betrifft, so ist es nicht nöthig, diesclben näher zu schildern, da sie in allen Einzelheiten den Luteinzellen der Cystenwandungen gleichen. Sie sind somit auch als solche aufzufassen. In Bezug auf die Lagerung dieser Zellen zu einander und gegenüber dem umgebenden. Bindegewebe finden sich die verschiedenartigsten Bilder. So siebt man sehr oft von der Luteïnzellenschicht der Cystenwandung aus einen Strang von Luteïnzellen in das umliegende Bindegewebe abbiegen und sich mehr oder weniger weit darin erstrecken. Die Mächtigkeit dieser Stränge ist eine sehr wechselnde. Bald sind sie ganz schmal, nur ans wenigen nobeneinander gelagerten Zellen bestehend, bald sind es mehr kurze zusammengeballte Haufen. Keineswegs jedoch bleibt die Breite dieser Stränge in sich immer dieselbe, sondern oft sieht man einen schmalen Zellzng plötzlich viel mächtiger werden, gewissermaassen knotig anschwellen, und umgekehrt einen dichten Haufen in einen feinen Ausläufer enden. Zumeist sind diese Zellzüge scharf gegen das umliegende Bindegewebe abgegrenzt. Hin und wieder jedoch liegen in nächster Umgebung von ihnen ein oder wenige Lutë̈nzellen, so dass man dann nicht immer sicher bestimmen kann, wie breit der Streilen ist, ob diese Zellen mit in ihn hineingehören, gewissermaassen nur von ihm abgesprengt sind, oder ob sie in keinem Zusammenhang mit ihm stehen. Die Richtung, in der die Stränge von der Zellschicht der Cystenauskleidung abbiegen, ist selten eine stumpt-, meist eine spitzwinklige; hin und wieder ziehen sie sogar auf weite Strecken parallel mit derselben, und nur an einer Stelle kann man den Zusammenhang beider feststellen.

Ausserdem aber bemerkt man vielfach Haufen oder Stränge von Luteinzellen frei im Bindegewebe liegen, ohne dass es mög- 
lich ist, irgend eine Verbindung derselben mit der Lutënschicht der Cystenwand aufufinden. Die Verbreitung dieser Herde ist eine sehr wechselnde. Manchmal sieht man in mehreren Gesichtsfeldern keinen einzigen, und andererseits kann ihre Zabl in einem Gesichtsfeld auf $20-30$ steigen, sodass man im ersten Augenblick den Eindruck empfängt, als hätte man ein Carcinoma simplex vor sich, welches in kleinen Herden seinen Nutterboden üppig durchsetzt hat. Das diese zelligen Gebilde einhüllende Bindegewebe ist fast immer unverändert. Hin und wieder jedoch hat es sich um dieselben verdichtet und sich mit der Längsrichtung seiner Fasern concentrisch angeordnet, so dass es gewissermaassen eine Kapsel um dieselben bildet. Manchmal findet man in ihm auch - allerdings nur ganz vereinzelt - kleinzellige Infiltration, die jedoch nie von bedeutender Ausdehnung ist. Oefters liegen in der Umgebung speciell grösserer Zellhaufen eigenthümlich gestaltete Gebilde, welche aus feiren, zumeist geschlängelten Bändern von hyaliner Beschaffenheit bestehen, die sehr an Residuen alter Corpora candicantia erinnern. Es macht den Eindruek, als ob man in diesen grösseren Zellherden weisse Körper vor sich hat, deren ursprüngliches Gewebe nicht hyalin degenerirt ist, sondern sich unter der Einwirkung irgend eines Proliferationsvorganges in Luteingewebe umgewandelt bezw. in seinem ursprünglichen Aufbau verharrt hat. An mehreren Stellen fanden sich Luteïnzellenhaufen in Spalträumen des Bindegewebes, die sicher als präexistirende Lymphspalten aufgefasst werden müssen.

Es bleibt mir nun noch übrig, den mikroskopischen Aufbau der gelb-bräunlichen Herde zu besprechen, die oben bei der makroskopischen Beschreibung als in den Cystenwandungen gelegen geschildert wurden. Eine auffallende Aehnlichkeit dieser Herde mit den soeben geschilderten besteht darin, dass auch sie aus Luteinzellen zusammengesetzt sind. Andrerseits finden sich aber auch nicht unbeträchtliche Unterschiede. So sind vor Allem diese Herde grösser und zejgen fast immer eine bestimmte Anordnung ihrer Zellen, die bei allen die gleiche ist. Der Aufbau der weitaus grössten Zahl von ihnea ist folgender: An das Ovarialstroma schliesst sich nach innen zu eine verschieden breite Schicht von Bindegewebe, welches diesem sehr ähnelt, aber in seinem Aufbau ein dichteres Gefüge zeigt und kernreicher ist. Im Grossen und Granzen sind seine Fasern concentrisch zum Mittelpunkt des Herdes angeordnet. Hierauf folgt eine verschieden breite Schicht ron Lu- 
teïnzellen, die zumeist in radiären Säulen gruppirt sind, welche vielfach eine Länge von 20 Zellen und darüber besitzen. Selten. tritt diese Anordnung der Zellen nicht so deutlich hervor; an einzelnen Herden ist es kaum möglich, auch nur Andeutungen. einer solchen zu constatiren, sondern die Zellen liegen regellos. durcheinander. Thre Contouren sind fast durchweg deutlich erkennbar, auch ist ihre Färbung eine gute. Nur selten trifft man Zellen, welche schwach gefärbt sind (im Gegensatz zu den übrigen), ganz vereinzelt solche, die fast völlig ungefärbt sind, so dass man ihr Vorhandensein mehr ahnen als sehen kann. Hauptsächlich trifft dies auf die im Innern des Herdes gelegenen Zellen zu. Keineswegs besteht immer eine scharfe äussere Abgrenzung des. Luteïnherdes, sondern sehr oft sieht man Zellzüge von demselben nach aussen wegziehen, um sich verschieden weit in das umliegende Bindegewebe zu erstrecken. Fast überall ist ein deutliches Gerüst von Bindegewebe zwischen den Zellen vorhanden, welches von feinen Capillaren begleitet ist und seinen Ursprung von der äusseren Bindegewebssehicht nimmt. Die Mächtigkeit derselben ist sehr verschieden. Bald sind nur ganz vereinzelte Züge vorhanden, die grosse Gruppen von Lutë̈nellen umschliessen, bald sind sie äusserst zahlreich vertreten, so dass die von ihnen gebildeten Maschen oft nur 3-4-5 Zellen beherbergen. In letzterem Falle ist zumeist auch ihre Dicke eine relativ bedeutende. Nach dem Centrum zu vereinigen sich die Bindegewebsbündel zu einem den Kern des Herdes darstellenden Complex von Bindegewebe, welches selten ein festeres Gefüge zeigt, sondern zumeist lockerer gebaut ist, manchmal sogar einen ödematösen Charakter annimmt, so dass man fast von einem gallertigen Bindegewebe sprechen kann.

Das soeben geschilderte Bild entspricht völlig dem, wie es typische Corpora lutea vera in normalen Ovarien aufweisen. Hin und wieder aber weicht der Aufbau der hier in Rede stehenden Gebilde nicht unbedeutend von diesem gewöhnlichen Befunde ab. Die Luteïnzellenschicht ist nur wenig hoch und die sie von aussen her durchziehenden Bindegewebsbündel vereinigen sich nach innen zu bald zu einem schmalen Bande. Der Vorgang hierbei ist der glciche, wie er oben bei einem Theil der Luteïncysten geschildert wurde. Man sieht die Bindegewebsbündel zusammen mit einem: Theil der in ihnen verlaufenden Capillaren in scharfem Winkel umbiegen, sobald sie die Luteïnschicht durchdrungen haben, und 
sich auf die Oberfläche derselben auflegen. Grössere Mächtigkeit nimmt das dadurch entstehende bindegewebige Band jedoch nie an, sondern es besteht immer nur aus wenigen neben einander verlaufenden Fasern. An diese Schicht schliesst sich nun centralwärts entweder ein kleiner, das Centrum des Herdes bildender Hohlraum an, der Detritusmassen in sich birgt. Oder aber zwisehen diese and das bindegewebige Band schiebt sich noch eine andere, zumeist ziemlich dicke Schicht dazwischen, welche aus einem kernarmen Bindegewebe besteht, das fast in seiner ganzen Breite einen mehr myxomatösen Charakter trägt und von vielen kleinen, wohl durch Oedem entstandenen Hoblräumen durchsetzt ist. Nur an seiner inneren und äusseren Begrenzung ist es fester gefügt. Aussen ist dies weniger der Fall, dort fehlen hauptsächlich nur die ödematösen Maschen. Innen dagegen treten allmälig breitere Fasern auf, welche je mehr central, je dichter aneinander gelagert sind, fast überhaupt keine Kerne zeigen und ein welliges Gefüge besitzen. Bei van Gieson'scher Färbung sind sie intensiv roth tingirt. Man geht wohl nicht fehl, wenn man hier an elastische Fasern denkt. Der dann centralwärts folgende, zumeist sehr kleine Hohlraum enthält Detritus, Blutpigment und wenige noch erhaltene rothe Blutkörperchen, zwischen denen vereinzelte, wohl aus Fibrin bestehende feine Fasern hinziehen, die sich sternartig durcheinander verflechten.

Manchmal übrigens kann das Bindegewebe, welches zwischen die Luteïnzellen hineingewuchert ist, derart mächtig sein, dass es auf Strecken hin den Eindruck macht, als wären in dasselbe ohne jegliche bestimmte Anordnung Luteinzellenhaufen hineinversprengt, und erst durch genauere Besichtigung des Herdes und Verfolgung der Luteinzellen in der ganzen Peripherie desselben wird man sich über die richtige Deutung dieser Bilder klar.

Ein kleinerer Theil dieser makroskopisch sichtbaren, gelbbräunlichen Herde zeigt jedoch ein anderes Gefüge. Der Kern, welcher die Hauptmasse dieser Gebilde ausmacht, besteht aus $れ-$ meist gut erhaltenen rothen Blutkörperchen, zwischen denen mehr oder weniger feine Fibrinfasern liegen, welche sich sternartig durehkreuzen und so gewissermaassen Maschen bilden, in denen die Blutkörperchen in Klumpen angehäuft sind. Zwischen diesen finden sich theils mehr oder weniger ausgedehnte Anbäufungen von Blutpigment, theils eigenartige, ralativ breite, regelmässig gefärbto Bänder, welche oft parallel zu einander verlaufen und nur bei 
genanerer Betrachtung eine gerade noch sichtbare Structur erkennen lassen, aus der heraus man den Eindruck gewinnt, als handele es sich hier um nekrotisch zu Grunde gegangene Luteïnzellenbänder. Umgeben sind diese das Centrum bildenden Massen von einer verschieden dicken (aber fast nie unter 3-4-5 Zellen breiten) Schicht von Luteïnzellen. Selten fehlt dieselbe völlig; dann reicht das Ovarialstroma direct an das Centrum des Herdes, wobei es an Kernreichthum verliert und dichteres Gefüge annimmt. Zumeist finden sich auch bei diesen Herden zwischen den Luteinzellen Bindegewebsbündel, von denen aus feine Fasern in die centralen Massen hineinziehen. Hierdurch findet anscheinend eine allmählich fortschreitende bindegewebige Substitution des Kernes statt. Manehmal ist dieser Process soweit vorgeschritten, dass das Luteinzellenlager auf Strecken hin von dem Kern durch einen mehr oder weniger breiten Saum von lockerem, mässig kernreichem and aus ganz feinen Fibrillen bestehendem Bindegewebe getrennt ist.

Kurz sei noch erwähnt, dass der bei der makroskopisehen Beschreibung des Präparates I ausführlich geschilderte, grosse, gelbbraune, scharf umgrenzte Herd sich bei der mikroskopischen Untersuchung als ein typisches Corpus luteum verum erwies.

Ueberblicken wir nun die oben angegebenen Befunde, so sehen wir, dass die Ovarien in unseren sämmtlichen Fällen ejgenthümliche Veränderungen eingegangen waren, welche überall die gleichen waren. Ich möchte hierbei nochmals betonen, dass der Befund bei der Blasenmole in Nichts von dem bei den syneytialen Tumoren abwich. Die Ovarien sind cystisch degenerirt und die Wandung jeder einzelnen Cyste enthält eine mehr oder weniger breite, verschiedenartig gestaltete Schicht von Zellen, die ich nach oben Gesagtem berechtigt zu sein glaube, als Luteinzellen anzusprechen. Zellen desselben Charakters durchsetzen herdweise das Bindegewebe, welches in den Zwischenwandungen der einzelnen Cysten liegt, in verschieden starker Ausdehnung. Manchmal sind es nur wenige zusammen liegende Zellen, manchmal Haufen von ganz bedeutendem Umfang. Theils ist die Aneinanderlagerung dieser Zellen eine unregelmässige, theils, wenigstens in den grösseren Herden, eine zumeist yanz typische. Verschiedenartig ist auch der Zusammenhang dieser Zellhaufen mit der Luteinschicht der Cystenwand. Bald bestehtein solcher, bald wird ervölligrermisst. 
Was die Cystenauskleidung betrifft, so sahen wir dieselbe aus verschiedenen Schichten bestehen. Charakteristisch für sie bleibt aber immer das in ihr liegende Luteinzellenband. In Bezug auf die der Luteïnschicht nach innen zu aufliegenden Massen bin ich derselben Ansicht wie Stoeckel (27). Ich glaube nicht, dass es sich hier um verschiedene Typen von Luteïncysten handelt, wie L. Fränkel (7) annimmt, sondern wir haben hier wohl nur theils Zufälligkeiten, theils verschiedene Stadien der Entwicklung der Cysten vor uns. Denn man sieht oft mehrfach eng neben den Niederschlägen von Fibrin oder Blut in ein und derselben Cyste Partien der Wand, die entweder von Bindegewebe bedeckt sind oder überhaupt keine Auflagerungen besitzen. Irgend eine Gesetzmässigkeit in dem Vorkommen der einen oder der anderen derselben lässt sich nirgends erkennen. Das den Wandungen der Cysten aufliegende Blut oder Fibrin verdankt seinen Ursprung wohl dem Platzen kleiner nahe der Innenfläche derselben gelegener Gefässe. Hierdureh gelangen vinerseits Blutkörperchen in den Inhalt der Cysten und senken sich hier ihrer Sehwere nach, um sich irgendwo der Cystenwand aufulegen, und andrerseits wird bei der naturgemäss stattfindenden Gerinnung des ausgetretenen Blutes Fibrin gebildet, das sich dann ebenfalls der Cysteninnenfläche anlegt. Betreffs des bindegewebigen Bandes auf der Luteinschicht könnte man ja daran denken, dass es sich hier nur um ein zufällig stärkeres Wuchern der zwischen den Luteïnzellen liegenden Bindegewebsbündel handelt. Aber jch möchte mich doch mehr der Ansicht zuneigen, dass wir hier rerschiedene Entwicklungsstadien vor uns haben: je älter die Cyste, um so stärker die Bindegewebswucherung.

Bei den sich makroskopisch als gelb-braune Herde markirenden grossen Anhäufungen von Luteinzellen haben wir es mit Bildungen zu thun, die in ihrem ganzen Aufbau und Anordnung sehr normalen corporibus luteïs gleichen, was sich durch die radiär-säulenartige Anordnung der.Zellen, die typische Dazwischenlagerung von Bindegewebe und den bindegewebigen Kern darthut. Auch die oft vorhandene myxomatöse Erweichung des letzteren findet sich bei corporibus luteïs.

Es erübrigt noch, die kleineren Herde von Luteïnzellen im Bindegewebe zu erwähnen, die entweder mit der Luteïnschicht der Cystenauskleidung in Verbindung stehen oder völlig isolirt daliegen. 
Wie diese Bildungen zu deuten sind, darauf wollen wir später eingehen.

Was nun die grossen Herde betrifft, deren Inneres liauptsächlich aus Blut und deren Peripherie aus einer Luteïnschicht besteht, so darf man wohl annehmen, dass es sich hier ursprünglich um Gebilde handelte, die mit den eben erwähnten, den corporibus luteis gleichenden, identisch sind. Durch das Platzen eines grösseren Blutgefässes ist es bei thnen aber zu einer ausgedehnten Blutung in das Innere gekommen. Man wird sich allerdings fragen, wie es möglich ist, dass der Bluterguss solche Ausdehnung hat annehmen können: Es wäre ja nun möglich, dass ein präexistirender Hohlraum da war, in den es hat hineinbluten können. 1ch glaube aber eher, dass der Bluterguss zuerst ein viel kleinerer war, dass aber unter dem Druck desselben auf das umliegende Luteingewebe Theile desselben zu Grunde gegangen sind, und dadurch für die weitere Ausdehnung des Ergusses Raum geschaffen worden ist. Hierför spricht auch der Befund der fast structurlosen Streilen zwischen den Blutkörperchen, die ich, wie schon oben erwähnt, für Luteinzellenbänder halte, die durch Drucknekrose zu Grunde gegangen sind, somit also das Gewebe repräsentiren, welches durch eigenen Untergang für die weitere Ausdehnung des Ergusses Platz gesehaffen hat.

Vergleiche ich nun diese meine Befunde mit denen von Neumann (17), Poten-Vassmer (20), Schaller-Pförringer (21) und Stoeckel (27), so bin ich der Ansicht, dass dieselben völlig mit einander identisch sind. Neumann (17), der allerdings nur eine kurze mikroskopische Beschreibung giebt, sah dieselben. Anhäufungen von Luteïnellen im Bindegewebe. $O b$ in seinem Falle auch in den Cystenauskleidungen Lager von Luteinzellen sich rorfanden, giebt er nicht an, bezw. ist nicht anzunehmen, da er sonst wohl darüber berichtet haben würde. Er fasst die Cysten als Follikelcysten auf. Ich glaube jedoch nicht, dass hierin ein wesentlicher Unterschied zwischen unseren Befunden besteht, sondern nehme vielmebr an, dass er nur weitere Entwicklungsstadien der von mir gefundenen Luteincysten gesehen hat, bei denen durch den erhöhten Cysteninnendruck oder sonstige andere Momente die Luteïrschicht verloren gegangen ist. Auch nach der Ansicht von $\mathrm{Nagel}$ (16), der alle epithellosen Ovarialcysten ätiologisch auf corpora lutea zurückführt, würden seine Cysten als Luteüncysten aufzulassen sein.

Ebenso sehe ich zwischen dem Befund von Poten-Vassmer (20) und dem meinigen eine völlige Uebereinstimmung, nur dass es mir 
nirgends gelungen ist, die bei ihm unter der Tumoroberfläche sitzenden Knötchen in meinen Fällen nachzuweisen. $O b$ es sich hier um Gebilde handelte, die den von mir gefundenen gelb-braunen Herden ähneln, wage ich nicht zu entscheiden; glaube es auch kaum. In gleicher Weise stimmt der Befund von Schaller-Pförringer (21) auffallend mit dem von mir erhobenen überein. Allerdings fanden sich bei ihm die mit Blut erfüllten Herde anscheinend viel öfter als bei mir, aber sonst dürften sich unsere Befunde mit einander decken.

Noch mehr ist dies der Fall mit den von Stoeckel (27) beschriebenen Ovarialtumoren, die bis in die kleinsten Einzelheiten den meinigen gleichen. Nur eins konnte ich im Gegensatz zu ihm nicht so oft und ausgesprochen constatiren, nämlich das Hineinwachsen von Blutgefässen in die Luteïnschicht der Cystenwand von aussen her; ausserdem war es mir nicht möglich, der Luteinschicht aufliegende Granulosazellen zu constatiren.

Wie aber sind nun diese eigenthümlichen Veränderungen der Ovarien zu erklären? Sehen wir uns hierzu noch einmal kurz die Ansichten der eben erwähnten Autoren an. Neumann geht auf diese Frage nicht. näher ein, sondern glaubt vur die im Bindegewebe gefundenen Herde von Luteïnzellen für im Entstehen begriffene corpora albicantia ansprechen zu sollen. Poten und Vassmer lassen die Frage offen, ob es sich bei diesen Herden um mangelhaft zurückgebildete Reste ehemaliger corpora lutea handelt, oder um eine selbstständige abnorme Wucherung der Luteïnzellen. Schaller und Pförringer halten den ganzen Process für eine carcinomatöse Degeneration der Luteïzellen, indem sie diesen eine starke Proliferationsfähigkeit und ein selbstständiges Wachsthum zusprechen. Auf einen ganz anderen Standpunkt stellt sich Stoeckel, der an irgend einen malignen Process nicht glauben will, sondern der Ansicht ist, dass es sich hier nur um einen passiven Vorgang handelt. Er nimmt an, dass sowohl die frei im Bindegewebe liegenden als die mit der Luteïnschicht der Cystenwandung zusammenhängenden Herde von letzterer in der Art abgesprengt würden, dass Blutgefässe von aussen her in sie hinein wucherten, ein Process, der noch in dem ausgedehnten Oedem der Tumoren Unterstützung fände.

Was Neumann's Ansicht anbelangt, so geht derselbe zu wenig auf die verschiedenen Eigenthümlichkeiten der Bilder ein, um den ganzen Process zu charakterisiren und völlig zu erklären. 
Poten und Vassmer verhalten sich in Bezug hierauf ganz passiv. Mit der Ansieht ron Schaller und Pförringer stimme ich, wie meine späteren Ausführungen zeigen werden, im Grossen und Ganzen überein. Nur halte ich es für unwahrscheinlich, wenn man den ganzen Process für carcinomatös erklären wollte, wie es die Verfasser allerdings anch nur sehr vorsichtig thun, denn dazu gehört vor Allem erst einmal ein. stricter Beweis über die Abstammung der Luteinzellen: ob sie bindegewebiger oder epithelialer Natur sind. Darin möchte ich mich ihrer Ansicht aber völlig anschliessen, dass der Vorgang als ein activer aufzufassen ist, der auf einer starken Proliferationsfähigkeit der Luteïnzeilen beruht. Hieraus geht aber schon hervor, dass ich die Ansicht von Stoeckel, dass es sich hier nur um einen passiven Vorgang ohne jede active Betheiligung der Luteinzellen handelt, nicht zu theilen vermag. Denn es will mir nicht einleuchten, wie allein durch die Kraft der hineinwuchernden Blutgefässe solche Mengen von Zellen von der Luteinschicht der Cystenauskleidung abgedrängt werden können. Handelte es sich schliesslich nur um die Zellstränge und -Bänder, die mit derselben direct in Verbindung stehen, so wäre Stoeckel's Erklärung wohl noch möglich. Dass aber auch die zablreichen, zerstreuten Zellherde, die weit von den Cystenauskleidungen entfernt liegen und ohne jeden Zusammenhang mit ihnen stehen, diesem Vorgange ihre Entstehung verdanken, halte ich für ganz unwahrseheinlich. Auch selbst dann, wenn man als unterstützendes Homent noch das hochgradige Oedem hinzuzöge. Ausserdem sah ich oftmals mitten im Bindegewebe Herde von Luteinzellen liegen, die mit der Luteïnschicht gar nicht zusammenhingen, und in deren selbst weiteren Umgebung oedematöse Aufquellung des Bindegevebes nicht zu constatiren war.

Sodann kommt noch folgendes hinzu: Stoeckel berichtet, dass er vielfach Luteïnzellen und hyaline Streifen, die er als Reste von corpora albicantia anspricht, regellos durch- und nebeneinander liegen sah. Die Angabe, dass diese Zellen in Zusammenhang mit der Luteinschicht der Cystenwandungen standen, habe ich nirgends bei ihm finden können. Dann aber liegt doch wohl der Gedanke nahe, dass sie nicht ron dieser Schicht abstammen, sondern mit den früher an diesen Stellen vorhanden gewesenen corpora lutea generiseh zusammenhängen. Und diese Ansicht spricht Stoeckel auch einmal aus, aber nur um zu beweisen, dass die hyalinen Bänder Reste von corpora albicantia sind. Damit räumt er aber. 
auch einengenetischen Zusammenhang zwischen ihnen und den corpora albicantia ein. Dann aber ist es mir nicht recht verständlich, wie er sie mit der Luteinschicht der Cystenauskleidung in Verbindung bringen will. Geht man dagegen von der Ansicht der völligen Passivität der Luteïnzellen ab und spricht ihnen eine Proliferationsfähigkeit zu, so ist meines Erachtens auch der Ursprung dieser Zellen klargelegt.

Meiner Ansicht nach ist der Vorgang bei der Bildung dieser Form von Ovarialtumoren folgender:

Infolge irgend, eines vorläufig noch unbekannten Agens erwerben die Luteïnzellen cine weit über das gewöhnliche Maass hinausgehende Proliferationsfähigkeit. Diese giebt sich einmal dadurch kund, dass die auf Grund der Gravidität in jedem einzelnen Falle vorhandenen corpora lutea die gewöhmlichen Grenzen gegenüber dem*anliegenden Bindegewebe überschreiten, indem von ihnen aus Zellzüge in die Umgebung hineinwuchern. Und andrerseits entwickeln sich über das ganze Ovarialstroma hin isolirt liegende Herde von Luteïnzellen. Welchem Vorgange letztere ihre Entstehung verdanken, konnte ich leider nicht sicher feststellen. Donkbar wären verschiedene Möglichkeiten. So könnten die Zellen der corpora lutea nicht nur in das umliegende Bindegewebe wuchernde Sprossen hineinsenden, sondern auch in die nächstliegenden Lymphspalten hineinwuchern und in ihnen sich weitere Wege bahnen. Hierfür würden verschiedene, oben angeführte Bilder sprechen, wo sich Züge von Luteïzellen in Lymphspalten fanden. Ausserdem kämen vielleicht auch noch für die Entstehung dieser Herde die normalen Follikel und vor allem die Primärfollikel in Betracht, eine Ansicht, die auch Stoeckel ausspricht, und die viel an Wahrseheinlichkeit dadurch gewinnt, dass sich sowohl ausgebildete wie Primärfollikel in äusserst geringer Anzahl in den Tumoren vorfanden. Und schliesslich werden die vereinzelten Luteïnzellen, welche normaler Weise zusammen mit den in ihrer Nähe gelegenen hyalinen Bändern die Reste von corpora albicantia darstellen, auch wohl nicht völlig von dem ganzen Proliferationsprocess unberührt bleiben, sondern jetzt ebenfalls zu wuchern anfangen und sich vielleicht zu grösseren Luteinzellenherden entwickeln und damit schliesslich ihre frühere Gestalt mehr oder weniger wieder gewinnen.

Dass die hauptsächlich aus einem blutigen Kern bestehenden Herde ursprünglich wohl sicher den corporibus luteïs gleichende 
Gebilde waren und ihren jetzigen Aufbau dem Platzen eines Blutgefässes und dem daraus resultirenden, centralen Bluterguss verdanken, haben wir schon oben auseinandergesetzt.

In Bezug auf die Entstehung der Cysten wäre vielleicht folgender Vorgang denkbar: Das blutige Centrum der eben erwähnten Herde wird allmăhlich verflüssigt, und ebenso der bindegewebige, eventuell sogar schon myxomatöse Kern der den corporibus luteïs gleichenden Gebilde; ein Vorgang, wie er sich auch wohl bei der Bildung der gewöhnlichen Luteincysten zumeist abspielt. Ziehen wir hierbei nun noch als unterstützendes Moment die starke Fluxion heran, unter der die Ovarien während der Gravidität stehen und die daraus resultirende ausgedehnte ödematöse Durchtränkung des Gewebes, so ist es sehr wohl verständlich, dass cinerseits der Kern der den corporibus luteïs gleichenden Gebilde sich sehr leicht verflüssigen kann, und dass andrerseits die cinmal gebildeten Cysten durch starke Flüssigkeitstranssudation von aussen her in ihren Hohlraum hinein schnell an Grösse zunehmen können.

Ich möchte daher meine Anschaungen über die Bildung der vorljegenden Tumoren dahin summiren, dass wir es mit einem activen Vorgang zu thun haber, der auf einer äusserst starken Proliferationstendenz der Luteinzellen beruht ${ }^{1}$ ).

Zwei Fragen wird man sich nun vorzulegen haben: Was verleiht den Luteïnzellen diese starke Proliferationsfähigkeit? Besteht wirlilicb ein ätiologischer Zusammenhang zwischen diesen eigenartigen ovariellen Veränderungen und der Blasenmole bezw. den syneytialen Tumoren?

So viel jeh aus der Literatur ersehen konnte, ist das massenhafte Auftreten soleher Luteincysten in einem bezüglich beiden Ovarien bisher nur bei Blasenmole bezw. syncytialen Tumoren beobachtet worden. Die Frage, ob ein ätiologischer Zusammenhang besteht oder nicht, beantwortet Baumgart (2) überhaupt nicht. Marchand (12) ist der Ansicht, dass cystische Neubildungen der Ovarien als ätiologisches Moment bei der Entstehung einer Blasenmole anzusehen seien. Auf denselben Standpunkt stellt sich

1) Wie ich einer Mittheilung von Herrn Dr. Albert-Dresden entnehme, beobachtete er einen Fall, wo sich zur Zeit der Ausstossung einer Blasenmole doppelseitige fast faustgrosse Ovariallystome vorfanden. Nach Ablauf von zwej Monaten hatten sich diese spontan roliständig zurüokgebildet. 
Kreutzmann (10). Matwejew und Sykow (15) halten die ovariellen Veränderungen für das Primäre.

Auf obige Fragen eine abschliessende Antwort zu geben, wage ich nicht, da ich der Ansicht bin, dass erst noch weitere Beobachtungen nöthig sind, um sich nach der einen oder der anderen Richtung hin zu entscheiden. Nur das Eine möchte ich betonen, dass ich es zum Mindesten für unwahrscheinlich balte, dass es sich hier nur um ein zufälliges Zusammentreffen handelt. Denn einerseits ist die Zahl der einschlägigen Beobachtungen jetzt schon eine zu grosse, um dies wahrscheinlich zu machen, und andrerseits hätten dann doch eigentlich diese auffallenden ovariellen Veränderungen auch einmal zur Beobachtung kommen müssen, ohne mit Blasenmole bezw. syneytialen Tumoren combinirt zu sein.

Vielleicht wäre es nicht ganz unrichtig, wenn man sich dahin ausspräche, dass diese Eierstocksveränderungen nur bei syncytialen Tumoren bezw. Blasenmole vorkommen, dass os abernichtunbedingt nöthig ist, dass sie immer Begleiterscheinungen derselben sein müssen ${ }^{1}$ ).

Zum Schluss möchte ich jedoch nicht unterlassen, einige theoretische Möglichkeiten hier anzudeuten, die vielleicht den Zusammenhang zwischen diesen ovariellen Veränderungen und den syncytialen Tumoren bezw. der Blasenmole erklären könnten. Ich möchte hierbei jedoch besonders hervorheben, dass es sich nur um Theorien handelt, für die ich leider stricte Beweise zu erbringen nicht in der. Lage bin. Hofmeier (9) giebt an, dass dem Ovulum, wenn es den Follikel verlässt, noch eine Anzahl Granulosazellen anhaften, die der Corona radiata entstammen. Unter der Voraussetzung nun, dass die Luteïzellen fon der Membrana granulosa abstammen, und dass dieser unter gewissen Umständen die Ursache für eine besondere Proliferationsfähigkeit innewohnen kann, wäre Folgendes denkbar: Einmal würden die Luteinzellen infolge

1) Kinen eigenartigen Fall, der anfangs gegen, dann aber deutlich für diese Ansicht sprach, theilte mir Herr Ober-Med.-Rath Dr. Sc h morl kürzlich mit. Vor kurzer Zeit erhielt er einen Ovarialtumor zur Untersuchung zugeschickt, der in seiner mikroskopischen Structur genau den hier in Rede stehenden Tumoren entsprach. Der operirende Arzt lonnte darüber, ob die betreffende Frau eine Blasenmole geboren batte, keine Auskunft ertheilen; wohl aber ergab dic Anfrage bei dem Hausarit das ubberasehende, aber erwartete Resultat, dass thatsächlich zwei Jahre vor der Operation eine Blasenmole geboren war. 
64 Runge, Ueber die Veränderungen der Ovarien bei syncytialen Tumoren

ihrer Herkunft von der Membrana granulosa stark wuchern und die oben beschriebenen Veränderungen an den Ovarien hervorrufen. Andrerseits würde aber auch das Syncytium, welches nach der Ansicht Hofmeier's von diesen mitgeschleppten Zellen der Corona radiata abstammt, infolge dieser Herkunft eine starke Proliferationsfähigkeit besitzen und damit den Anlass zu der Bildung der Blasenmole bezw. den syncytialen Tumoren abgeben. Unter diesen Annahmen würde ein ursächlicher Zusammenhang zwischen diesen und den Ovarialtumoren gefunden sein. Eine andere Erklärungsmöglichkeit wäre vielleicht folgende: Fränkel hat nachgewiesen, dass die Entwicklung des Eies in dem Uterus abhängig ist von der Integrität des zugehörigen Corpus luteum, und somit ein inniger Zusammenhang zwischen beiden besteht. Infolge hiervon wäre es denkbar, dass, wenn dem Corpus luteum unter besonderen limständen eine erhöhte Proliferationsfähigkeit innewohnt, diese sich auch auf das Ovulum fortpflanzte und hier zu den eigenartigen Veränderungen führte, die wir unter dem Bilde der Blasenmole bezw. der syncytialen Tumoren sich abspielen sehen. Dagegen sprechen würde allerdings der Befund Schlagenhaufer's von syneytialen Tumormassen in Hodenteratomen, denn damit wäre jeglicher specifische Zusammenhang zwischen den syncytialen Tumoren und den weiblichen Genitalien unterbrochen.

Wie aber soll sich nun der Kliniker diesen Ovarialtumoren gegenüber verhalten? Hierauf eine abschliessende Antwort zu geben, ist vorläufig nicht angängig, denn dazu gehören erst weitere Beobachtungen. Rathsam wäre es aber wohl immer, derartige Fälle nicht aus dem Auge zu lassen, um die Tumoren zu entfermen, wenn sie auch nach Ablauf der Schwangerschaft unaufhaltsam weiter wachsen. Macht sich zwecks Entfernung der syncytialen Tumoren so wie so eine Eröftnung der Leibeshöhle nothwendig, so wäre es wohl richtig, wenn man gleich hierbei die Ovarialtumoren operativ beseitigte. Auf alle Fälle nöthig würde dies natürlich werden, wenn der Nachweis ihrer Malignität sicher erbracht würde.

Zum Schluss möchte ich noch einige Veränderungen an Corpora lutea bezw. Corpus-luteum-Cysten erwähnen, die ich bei der Durchsicht ciner ganzen Reihe derartiger Gebilde zu beobachten Gelegenheit hatte. Es handelt sich einmal um zwei Corpus-lufeum-Cysten, in denen ein einschichtiges Epithelband lag, und terner um Einschlüsse in zwei Corpora latea, von denen der eine 
avis einem kubischen Epithel, der andere aus Ovarialstroma. bestand.

Was die Corpus-luteum-Cysten betrifft, so ist das Bild derselben folgendes: Man sieht in dem Innenraum der Cysten ein schmales Band von Zellen, die nebeneinander gelagert sind und eine kubische Gestalt besitzen. Im Gegensatz zu den Luteinzellen sind sie kleiner, viel schärfer contourirt, und ihre Abgrenzung gegen einander ist bedeutend genauer. Sie sind sehr intensiv getärbt, wenigstens ihre Kerne. Dieses Band, welches in beiden Fällen aus ca. 30 bezw. 40 derartigen Zellen besteht, berührt theilweise die Cystenwand, lässt sich aber scharf von den daneben liegenden Luteïnzellen unterscheiden, theils ragt es in das Innere der Cysten hinein. Derartige epithelhaltige Corpus-luteum-Cysten haben schon mehrere Beobachter gesehen, wie Orthmann (19), Steffeck (26) und Doering (3). Alle diese Autoren führen den Ursprung des Epitheleinschlusses auf die Membrana granulosa zurück. Ich möchte aber noch auf eine andere Entstehungsmöglichkeit aufmerksam machen, nämlich, dass es sich um hineingestülptes Keimepithel handeln kann.

Den Vorgang hierbei denke ich mir folgendermaassen: In dem Augenblicke, wo der reife Follikel springt und der Liquor folliculi mit dero Ovulum nach aussen abfliesst, fallen die Follicularwände zusammen. Hierbei können sich naturgemäss die Ränder des Risses, die hauptsächlich aus Tunica albuginea mit darauf sitzendem Keimepithel bestehen, nach innen zu einstülpen. Verkleben nun diese Ränder mit einander, so haben wir einen Hohlraum vor uns, in dem Tunica albuginea und Keimepithel sich eingeschlossen finden. Entwickelt sich jetzt aus dem geplatzten Follikel ein Corpus luteum, so ist es ersichtlich, dass dieses eben diese Theile in sich bergen kann. Die Tunica albuginea betheiligt sich nun an der Bildung des bindegewebigen Gerüstes des Corpus luteum, und das verschleppte Keimepithel imponirt als ein einzeiliges Epithelband im Innern des Corpus luteum. Wandelt sich dieses in eine Cyste um, so wird auch in dieser das Epithel zu finden sein.

Theoretisch, wird man mir entgegenhalten, ist dieser Vorgang möglich, aber es fehlen dafür die Beweise. Nun, ich glaube Bilder gesehen zu haben, die ihn zum mindesten höchst wahrscheinlich machen. So fand ich oft in der Gegend der Narbe von corporibus luteïs eine mehr oder weniger tiefe Einziehung der 
Oberfläche, welche in ihrer ganzen Ausdehnung von Tunica albuginea mit darauf sitzendem Keimepithel gebildet wurde. Dies allein würde jedoch zur Bestätigung meiner Ansicht nicht genügen. Ich konnte aber ausserdem feststellen, dass an diesen Stellen von der Tunica albuginea aus bindegewebige Züge sich abzweigten und in scharfem Winkel umbicgend in das Innere des betreffenden Corpus luteum hineinzogen, un hier mit dem bindegewebigen Gerüst desselben in Verbindung zu treten. Des Weiteren konnte ich durch Serienschnitte hindurch an der Narbe eines corpus luteum Folgendes constatiren: Es fand sich eine tiefe, von der Oberfläche des Ovariums weit in das Gewebe des corpus luteum hineinziehende Einsenkung. In ihrer ganzen Circumferenz war sie von einer bindegewebigen Schicht ausgekleidet, die deutlich ron der Tunica albuginea abstammte und nach innen zu mit dem bindegewebigen Gerüst des corpus luteum in Verbindung stand. Ausserdem aber fanden sich überall in dem Lumen derselben, vereinzelt oder zu kurzen Bändern angeordnet, typisehe Keimepithelzellen. Allerdings war diese Einsenkung nach aussen zu nicht völlig abgeschlossen, sondern an dem Beginn derselben hatten sich die gegenüberliegenden Ränder nur bis auf einen ganz feinen Spalt genähert. Sehr wobl aber ist nun eine völlige Verklebung derselben denkbar, wodurch dann in dem corpus luteum ein Hohlraum entstanden sein würde, der typische Keimepithelzellen in sich barg und allseitig von Bindegewebe umgeben war, welches von der Tunica albuginea abstammte. Würde dieser Hohlraum nun an Grösse zugenommen haben, so wäre daraus schliesslich eine typische Corpas-luteum-cyste entstanden, in deren Jumen epitheliale Zellen lagen, die nichts anderes als Keimepithel waren.

Auf denselben Ursprung - das Keimepithel - führe ich auch das in einem kleinen Hohlraum eines corpus luteum gefundene einzeilige Epithelband zurück, welches in seinem ganzen Aufbau, sowie in der Structur seiner Zellen völlig dem. Keimepithel gleicht. Eine Abbildung dieser Stelle siehe in Figur I. Dass dasselbe nicht etwa irgendwo mit der Umgebung des corpus luteum in Verbindung stand, sondern einen völligen Einschluss in demselben darstellto, konnte jch durch Anlegung von Serienschnitten nachweisen. Bei Anwendung starker Vergrösserung zeigte es sich, dass diese Zellen Flimmerbesatz trugen. Im ersten Augenblick würde dieser Befund allerdings gegen meine Ansicht 
Figur 1.

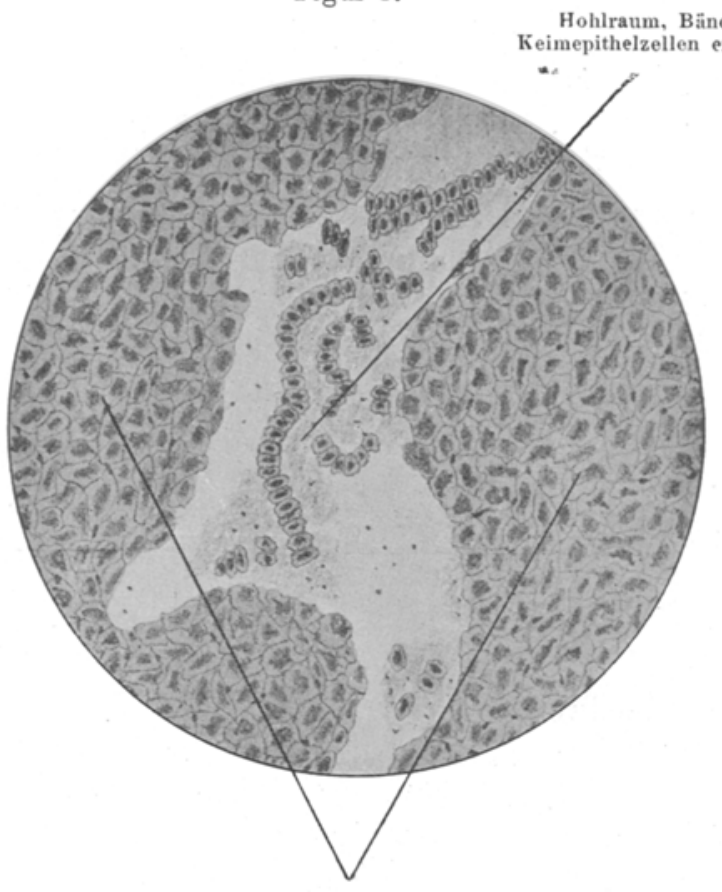

Luteīnzellen.

Figur 2.

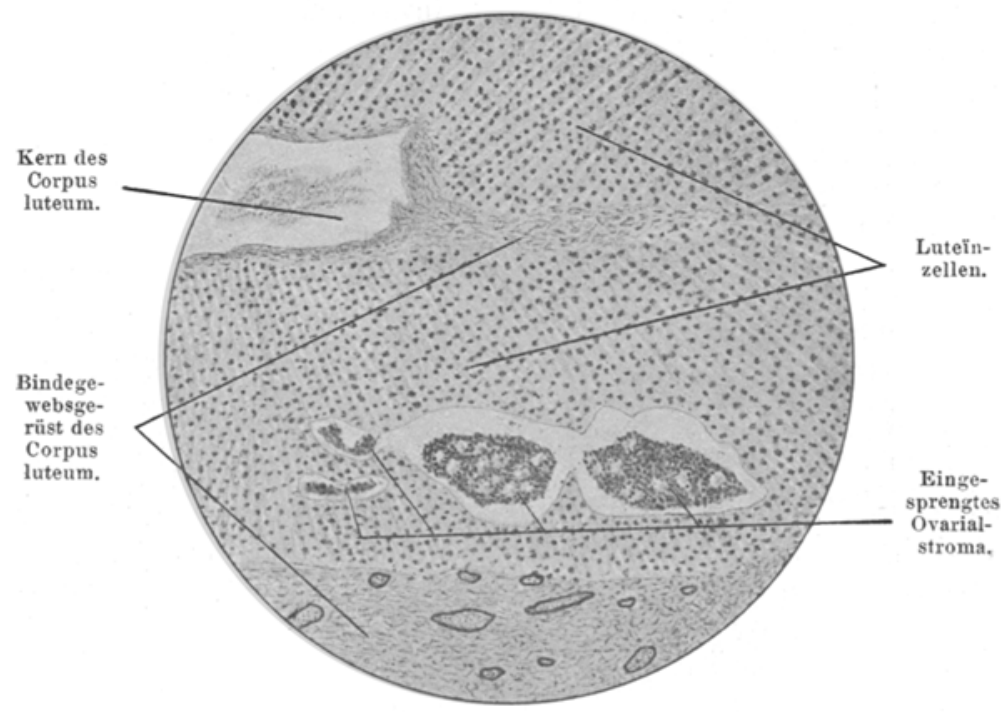


über ihre Abstammung vom Keimepithel sprechen, da letzteres bei ausgebildeten Ovarien nicht flimmert. Es ist jedoch ron Pick nachgewiesen worden, dass eingestülptes Keimepithel wieder flimmernd werden kann.

Als letzter eigenthümlicher Befund wäre dann noch der schon aben erwähnte Einschluss von Ovarialstroma in einem corpus luteum zu erwähnen. Das bezügliche Bild ist in Figur II wiedergegeben. Man sieht mitten zwischen den Luteïzellen eiven kleinen Herd intensiv gefärbten Gewebes liegen, das sich wohl durch die Behandlungsmethode etwas ron dem anstossenden Gewebe retrahirt hat. Bei der Verfolgung dieses Einschlusses durch Serienschnitte hindurch konnte ich feststellen, dass es sich um ein ziemlich langes, schmales Band handelt, welches das corpus luteum fast in der Hälfte seiner Breite durchzieht, aber auf allen Seiten von Luteingewebe abgeschlossen ist. (In dem gezeichneten Schnitt ist es infolge seiner welligen resp. gekrümmten Gestalt nur theilweise zur Darstellnng gekommen.) Nirgends steht es mit dem das corpus luteum umgebenden Ovarialstroma in Verbindung. Anfangs war ich zweifelhaft, was ich hier vor mir hatte; bei genauerem Zusehen und Anwendung stärkerer Vergrösserungen konnte ich jedoch feststellen, dass dieser Herd aus längeren und kürzeren, spindelförmigen, ziemlich intensiv gefärbten Bindegewebsfibrillen besteht, wie sie in gleicher Weise das Ovarialstroma zusammensetzen. Völlige Gewissheit hierüber gab mir der Nachweis von typischen Primärfollikeln zwischen den Bindegewebszellen. Damit aber war der sichere Beweis erbracht, dass es sich hier um Ovarialgewebe handelte. In welcher Weise dieses in das corpus luteum hineingelangt ist, war aus den Präparaten nicht ersichtlich. Aber man darf wohl bestimmt annehmen, dass dies in der Weise geschehen ist, dass die Luteïnzellen bei der Bildung des corpus luteum eine kleine Partie von Ovarialgewebe umwuchert und allmählich völlig in sich hineingezogen haben.

Zum Schluss erfülle ich die angenehme Plicht, Herrn OberMedicinal-Rath Dr. Schmorl für die gütige Ueberlassung des Materials und für die liebenswürdige Unterstützung bei der Untersuchung desselben auch an dieser Stelle meinen verbindlichsten Dank auszusprechen. 


\section{Einschlägige Literatur.}

1. Albert, Demonstrationen. Centralblatt f. Gyn. 1902. S. 431.

2. Baumgart, Blasenmole bei beiderseitigen Ovarialcysten. Centralbl. für Gyn. 1902. S. 96.

3. Doering, Beitrag zur Streitfrage über die Bildung des Corpus luteum. Anatom. Anzeiger. Bd. XVI. No. 12.

4. Fiedler, Beitrag zur Kenntniss der syncytialen Tumoren. Inang.-Diss. Kiel. 1900.

5. E. Fränkel, Ueber Corpus-luteum-Oysten. Dieses Arch. Bd. 48. S. 1.

6. E. Fränkel, Ueber Corpus-Iuteum-Cysten. Dieses Arch. Bd. 57. S. 511.

7. I. Fränkel, Der Bau der Corpus-Iuteum-Cysten. Dieses Arch, Bd. 56 . S. 353.

8. Goebel, Beitrag zur Anatomie und Aetiologie der Graviditas tubaria an der Hand eines Präparates von Blasenmole. Dieses Archiv. Bd. 55. S. 658 .

9. Hofmeier, Beiträge zur Anatomie und Entwicklung der menschlichen Placenta. Zeitschr. f. Geb. u. Gyn. Bd. 35. S. 414.

10. Kreutzmann, Cystic degeneration of the chorion villi with coincident cystic tumor of both ovaries. The amerie. Journ. of obstr. Vol. 37. p. 761. Refer: im Centralbl. f. Gyn. 1899. S. 190.

11. M a r ch a nd, Ueber die sogenannten, decidualen"Geschwülste im Anschluss an normale Geburt, Abort, Blasenmole und Extrauterinschwangerschaft. Monatsschr. f. Geb. u. Gyn. Bd. 1. S. 419 u. 513.

12. Marchand, Ueber den Bau der Blasenmolo. Zeitschr. f. Geb. u. Gyn. Bd. 32. S. 405.

13. Marchand, Ueber das maligne Chorionepitheliom, nekst Mittheilung von zwei neuen Fällen. Zeitschr. f, Geb. u. Gyn. Bd. 39. S. 173.

14. Martin, Die Krankheiten des Eierstocks und Nebeneierstocks. 1899. S. 92 und 333 .

15. Matwejew und Sykow, Blasenmole in der Tuba Fallopii und cystische Degeneration des Ovariums. Ref. im Centralbl. f. Gyn. 1902. S. 296.

16. Nagel, Beitrag zur Anatomie gesunder und kranker Orarien. Dieses Arch. Bd. 31. S. 327.

17. Neumann, Beitrag zur Kenntniss der Blasenmole und des malignen Deciduoms. Centralbl. f. Gyn. 1897. S. 1532.

18. Neumann, Beitiag zur.Lehre vom "malignen Deciduom". Monatsschr. f. Geb. u. Gyn. Bd. 3. S. 387.

19. Orthmann, Zur Pathologie des Corpus luteum. Centralbl. f. Gyn. 1897. S. 798 .

20. Poten u. Vassmer, Beginnendes Syncytiom mit Metastasen, beobachtet bei Blasenmolensolıwangerschaft. Dieses Arch. Bd. 61. S. 205.

21. Schaller u. Pförringer, Zur Kenntniss der vom Corpus luteum ausgehenden Neubildungen. Hegar's Beiträge zur Geburtsh. u. Gyn. Bd.Il. S. 91 .

22. Schmorl, Ueber malignes Deciduom. Centralbl. f. Gyn. 1893. S. 169. 
70 Runge, Ueber d. Veränderungen d. Ovarien b. syncytialen Tumoren etc.

23. Sc hmorl, Demonstration eines syncytialen Scheidentumors. Centralbl. $f$. Gyn. 1897. S. 1217.

24. Schottländer, Beitrag zur Kenutniss der Follikelatresie nebst einigen Bemerkungen über die unveränderten Follikel in den Eierstöcken der Sänglinge. Arch. f. mikroskop. Anatomie. Bd. 37. S. 192.

25. Sobotta, Noch einmal zur Frage der Bildung des Corpus luteum. Arch. f. mikrosirop. Anat. Bd. 53. S. 546 .

26. Steffeck, Zur Entstehung der epithelialen Eierstocksgeschwülste. Zeitschrift f. Geb. u. Gyn. Bd. 19. S. 236.

27. Sto ecke1, Ueber die cystische Degeneration der Ovarien bei Blasenmole, zugleich ein Beitrag zur Histogenese der Luteïnzellen. Festschrift für Fritsch. S. 136. 